\title{
THE RELATIONSHIP BETWEEN ELECTRICAL AND MECHANICAL EVENTS IN THE CARDIAC CYCLE OF MAN*
}

\author{
BY \\ B. COBLENTZ, $\dagger$ R. M. HARVEY, M. I. FERRER, \\ A. COURNAND, AND D. W. RICHARDS, JR. \\ From the Cardio-Pulmonary Laboratory of the Chest Service and the First Medical Division (Columbia University) \\ of Bellevue Hospital, and the Department of Medicine, College of Physicians and Surgeons, \\ Columbia University, New York City \\ Received July 24, 1948
}

In studying the dynamics of the heart beat, the relationship between electrical and mechanical events in the cardiac cycle has been of fundamental importance. The basic concepts of this relationship have been defined by Lewis (1925) and Wiggers (1923) and their co-workers. Sir Thomas Lewis provided indirect information on these events in the right auricle of man. Animal experiments, supplemented by such indirect information as could be obtained from venous and arterial pulse wave tracings, recording of heart sounds, etc., in man were used by Wiggers to anticipate the probable normal sequence of events in the cardiac cycle.

More precise information may now be obtained using the method of right heart catheterization. With direct measurements from within the right heart chambers and pulmonary artery, coupled with peripheral arterial pulse wave and electrocardiographic recordings, the normal course of electrical and mechanical events may be more clearly defined in man and abnormalities in contraction and conduction of the diseased heart may be further elucidated.

The data thus obtained will supplement the results obtained by many other investigators and will be analysed and discussed in the light of their studies.

\section{Method of Study}

In this study recordings of blood pressures in the auricle, ventricle, pulmonary artery, and brachial artery were made simultaneously with the electrocardiogram. The method of catheterization of the right heart, introduction of the indwelling arterial needle, and recording of pressures has been previously described (Cournand and Ranges, 1941; Cournand et al., 1944; and Bloomfield et al., 1946). In some instances a double lumen catheter was used (Cournand et al., 1945), permitting the simultaneous recording of pressures in the right auricle and ventricle or the right ventricle and pulmonary artery. In order to obtain satisfactory records of these pressures, manometers of varying sensitivities were used. Only the records that permitted the exact determination of the onset of rise of pressure in the right heart or in the arteries were used. The electrocardiograph was of the string galvanometer type and tracings were usually made on standard lead II. The speed of the camera could be varied from 12.5 to $50 \mathrm{~mm}$. a second, permitting time intervals to be estimated correctly to within $0.010 \mathrm{sec}$. It has been shown repeatedly that no parallax exists between the light beams of the manometers and the electrocardiograph. A method for determining the time lag in mechanical transmission of an impulse through the catheter at $37^{\circ} \mathrm{C}$. has been previously described (Cournand et al., 1946), and on repeated determinations was found to be $0.010 \mathrm{sec}$. This applies to the initial pressure rise only. In analysing the records, a correction was therefore made by subtracting 0.010 sec. from the measured values of the time intervals between the beginning of electrical and the beginning of mechanical events. In the present state of recording blood pressures in the right heart it is possible to determine exactly the point at which an initial pressure rise takes place. Because there is great uncertainty as to the accuracy of the records during the period of decline of pressure, analysis of the pressure curves during diastole was not attempted.

* This work was supported by a grant from the Commonwealth Fund with additional aid from the Life Insurance Medical Research Fund.

$\dagger$ French Government Research Fellow in Medicine.

B 
The following measurements were made in analysing the records and the following symbols will be used in presenting the data. in man, "the upstroke of $P$ precedes the upstroke of ' $a$ ' in the human jugular curve by from $0 \cdot 100$ to $0 \cdot 150 \mathrm{sec} . "$

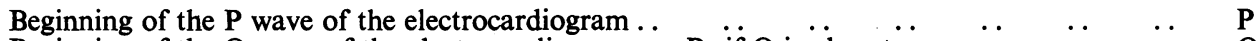

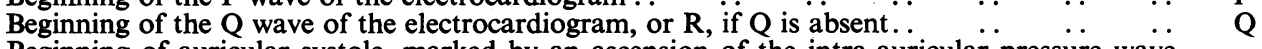

$$
\begin{aligned}
& \text { Beginning of auricular systole, marked by an ascension of the intra-auricular pressure wave } \\
& \begin{array}{c}
\text { near the end of the diastolic period . . . } \\
\text { Beginning of right ventricular systole, occurring at the end of diastole when the curve shows } \\
\text { a steep rise }
\end{array} \\
& \begin{array}{l}
\text { Beginning of ejection in the pulmonary artery, marked by the rise of pressure in the artery, at } \\
\text { the end of the descending diastolic curve }
\end{array} \\
& \begin{array}{c}
\text { Beginning of the systolic pressure rise in the brachial artery at the end of the descending } \\
\text { diastolic curve }
\end{array}
\end{aligned}
$$

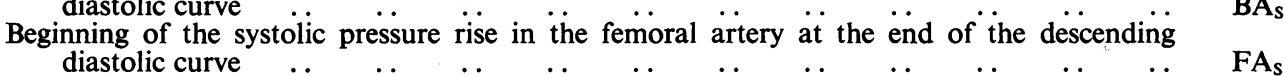

The material for study was selected by analysis of all the records that had been obtained in the course of several years from normal subjects, children with congenital heart disease, and a variety of patients with cardiac or pulmonary disease.

\section{Relationship Between Electrical and Mecha- NiCAL Events in Adults with EsSentially Normal Circulation}

In Table $I$ will be found the average figures relating electrical and mechanical events in subjects with essentially normal circulation. Representative normal tracings are illustrated in Fig. 1 and 3.

(a) The average time interval between the beginning of the $P$ wave and the beginning of the auricular systole $\left(P-A t_{s}\right)$ was $0.090 \mathrm{sec}$. in 16 cases. This interval is somewhat less than that of $0.110 \mathrm{sec}$., found previously in 8 adult subjects with normal hearts by Cournand et al. (1946). Lewis (1925) has previously described the following relationship in dogs: "The upstroke of $\mathbf{P}$ precedes the curve of shortening in the right auricular appendage, in six dogs, by from 0.024 to 0.043 sec." The above values are about one third of what was found in normal adults in this study. Lewis also states that
In order to evaluate the pulse wave velocity in the large veins, tracings were taken in some of the present studies as the catheter was progressively withdrawn from the right auricle to the axillary region. Although such tracings are few, figures indicate that the pulse wave velocity in the undistended large veins of normal man progresses at approximately 2.5 metres a second. Assuming an average distance of $10 \mathrm{~cm}$. from the right auricle to the bulb of the right jugular vein, approximately $0.040 \mathrm{sec}$. should be added to figures obtained by the catheterization technique in order to compare them with Lewis' figures in man.

(b) The average time interval between the beginning of $Q$ and the beginning of the right ventricular systole $\left(Q-R V_{8}\right)$ was $0.075 \mathrm{sec}$. in 30 cases. Lewis (1925) states that, " the beginning of the initial ventricular deflection usually precedes the onset of ventricular contraction, as estimated from myocardiograms from the front of the ventricle in six dogs, by from 0.020 to 0.038 of a second." Kahn et al. (quoted by Wiggers, 1923), recording pressures by means of a needle in the right ventricle of dogs simultaneously with an electrocardiogram, found that the time interval from $Q$ to the rise of pressure

\section{TABLE I}

Relationship Between Electrical and Mechanical Events in Adults with Essentially Normal Circulation

Heart rate per minute P-R interval, sec. . . QRS interval, sec. Q-BAs interval, sec. $\mathrm{P}-\mathrm{At}_{\mathrm{s}}$ interval, sec.

Q-RV interval, sec.
Q-PAs interval, sec.

End diastolic pressure in

Right ventricle, mm. Hg. .

Pulmonary artery, $\mathrm{mm}$. $\mathrm{Hg}$.
Average of 30 cases Average of 30 cases Average of 30 cases Average of 30 cases Average of 16 cases Average of 30 cases Average of 15 cases* Average of 15 cases* Average of 15 cases* Average of 15 cases*
80 $0 \cdot 160$ 0.080 $0 \cdot 160$ 0.090 0.075 0.072 0.085 $3 \cdot 0$ $3 \cdot 0$
$8 \cdot 0$ 0.013

\footnotetext{
* The same 15 cases were used to obtain these values.
} 


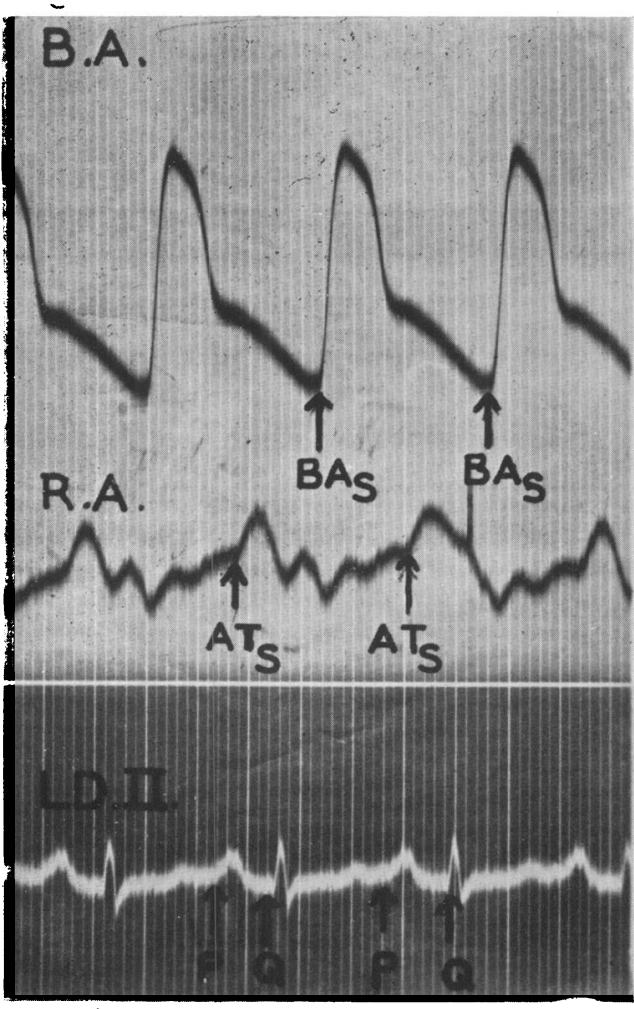

FIG. 1.-Record illustrating normal electricalmechanical time intervals in an adult subject. From top to bottom, blood pressure tracings in the brachial artery (B.A.) and the right atrium (R.A.), and electrocardiogram lead II. $\mathrm{P}-\mathrm{At}_{\mathrm{s}}=0.080 \mathrm{sec} . \quad \mathrm{Q}-\mathrm{BA}_{\mathrm{s}}=0.160 \mathrm{sec}$.

In this and all other records the distance between vertical lines is equal to $0.040 \mathrm{sec}$.

was from 0.031 to $0.035 \mathrm{sec}$. Garten (quoted by Wiggers, 1923), using an electrical manometer, found approximately the same interval -0.030 to $0.045 \mathrm{sec}$. An analysis of a tracing of Wiggers (1928) shows the same interval to be $0.040 \mathrm{sec}$. These figures in dogs are about one half of the values found in man in the present study. In an analysis of the time interval between the beginning of the electrical ventricular complex and the c wave in jugular tracings of man, Lewis states that, " the upstroke of $R$ precedes the upstroke of $\mathrm{c}$ in the human jugular by from 0.100 to 0.150 of a second." Miller and White (1941) found an identical value for the Q-c interval in man. Assuming that the $\mathrm{c}$ wave corresponds to the beginning of the mechanical contraction in the right ventricle and subtracting $0.040 \mathrm{sec}$. for its transmission to the jugular, the figures compare well with the $\mathbf{Q}-\mathbf{R V}_{\mathbf{s}}$ time as measured directly.

(c) The average time interval between the begin-

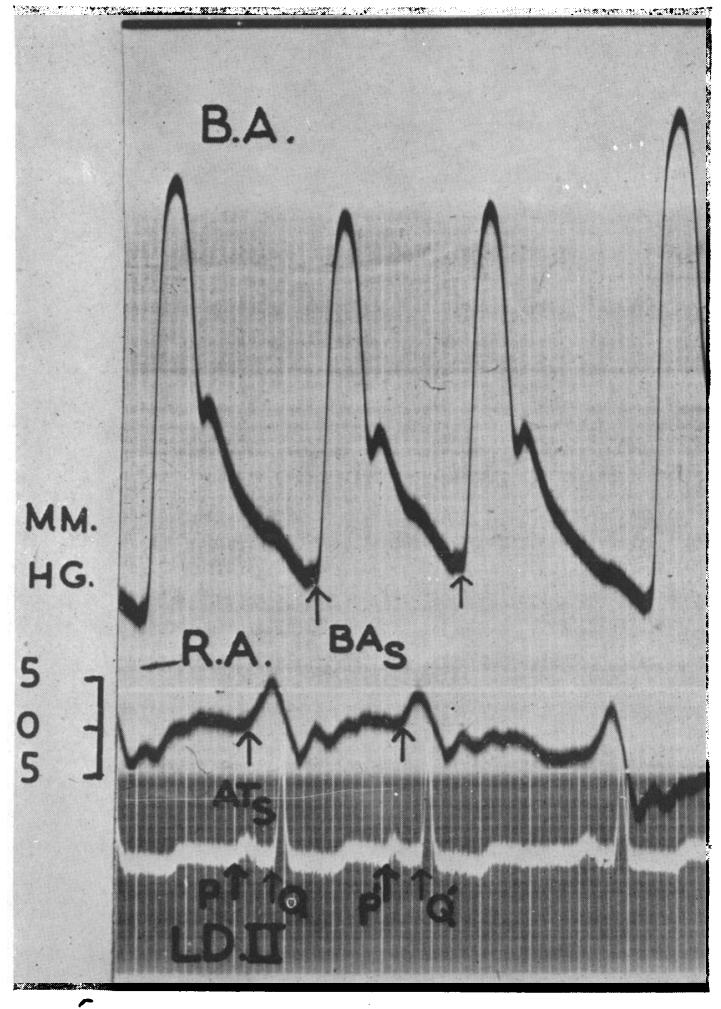

FIG. 2.-Record illustrating electrical-mechanical events in a case with auricular premature contractions.

From top to bottom, blood pressure tracings in the brachial artery (B.A.), the right atrium (R.A.), and electrocardiogram lead II. $\mathbf{P}^{\prime}$ and $\mathrm{Q}^{\prime}$ correspond to the premature beat.

ning of $Q$ and the beginning of the pulmonary artery systole $\left(Q-P A_{s}\right)$ was $0.085 \mathrm{sec}$. Using this time interval, it is possible to measure the duration of the isometric contraction of the right ventricle, i.e. the time required to raise the pressure from the end diastolic level in the right ventricle to the end diastolic level in the pulmonary artery. This time is calculated by subtracting the value of $Q-R V_{s}$ from Q-PAs. In 15 cases where both right ventricle and pulmonary artery pressures have been measured, the value for this interval was $0.013 \mathrm{sec}$. A tracing of simultaneous pulmonary artery and right ventricular pressures, taken with a double lumen catheter (Fig. $3)$, demonstrates the short duration $(0.010 \mathrm{sec}$.) of the isometric contraction in a normal subject. In the 15 cases studied, the average pressure values were, respectively, $3 \mathrm{~mm}$. $\mathrm{Hg}$ for the end diastolic pressure in the ventricle and $8 \mathrm{~mm}$. $\mathrm{Hg}$ for the end diastolic pressure in the pulmonary artery. A period 


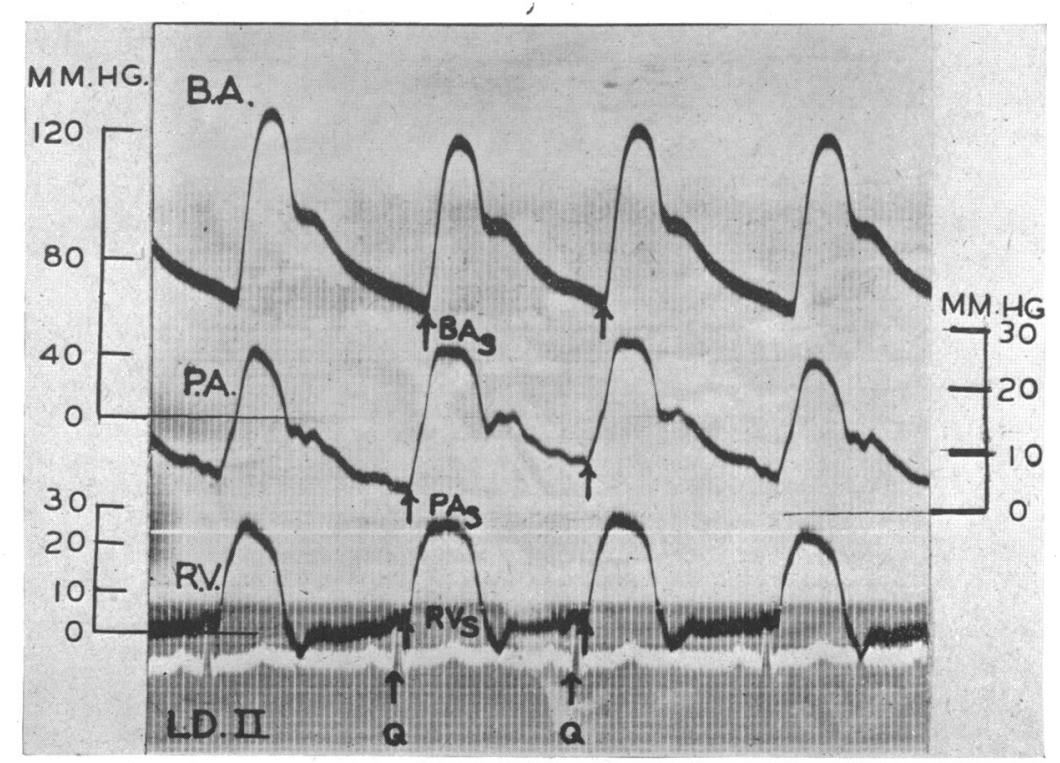

FIG. 3.-Record illustrating normal electrical-mechanical time intervals in an adult subject.

From top to bottom, blood pressure tracings in the brachial artery (B.A.), the pulmonary artery (P.A.), the right ventricle (R.V.), and the electrocardiogram lead II. The intracardiac blood pressure tracings were taken simultaneously with a double lumen catheter.

Note that the slope of the ascending pressure curves in the right ventricle and pulmonary artery do not exactly coincide. This may represent a genuine difference or be a manifestation of hysteresis in the recording. Regardless of the interpretation given to this difference, it has no bearing upon the choice of the exact site of the initial rise in pressure.

$\mathrm{Q}-\mathrm{RV}_{\mathrm{s}}=0.080 \mathrm{sec}$ Q-PAs $=0.090 \mathrm{sec} . \quad \mathrm{Q}_{-}-\mathrm{BA}_{\mathrm{S}}=0.160 \mathrm{sec}$

The duration of isometric contraction is $0.010 \mathrm{sec}$.

of $0.013 \mathrm{sec}$. was therefore necessary to raise the pressure in the right ventricle $5 \mathrm{~mm}$. $\mathrm{Hg}$ above the initial level in order to open the pulmonary valves.

(d) The average time interval between the beginning of $Q$ and the beginning of brachial artery systole $\left(Q-B A_{8}\right)$ was found to be $0 \cdot 160 \mathrm{sec}$. in 30 cases. Assuming that the pulse wave velocity does not vary greatly, this time interval is probably valuable in assessing indirectly the duration of isometric contraction of the left ventricle. By simultaneous registration of heart sounds, subclavian pulse, and the electrocardiogram in man, Wiggers (1944) estimated the duration of isometric contraction in the left ventricle to be from 0.040 to $0.060 \mathrm{sec}$. Katz and Feil (1923) found figures with a somewhat greater range, 0.024 to $0.089 \mathrm{sec}$. With an average duration of isometric contraction of the left ventricle of $0.050 \mathrm{sec}$., $0.110 \mathrm{sec}$. would be required for the pulse wave to be transmitted to the brachial artery. This corresponds approximately to a pulse wave velocity of 5 metres a second. Previously published values for the time interval between the beginning of $Q$ and the onset of pressure rise in the more proximal arteries will be found in Table II.

\section{Relationship Between Electrical and Mecha- NICAL EVEnTS IN ChILDREN WITH CongentTal Heart Disease}

In Table III will be found the average figures in children whose ages range from 5 months to 16 years. On the whole, the intervals were shorter than in normal adults.

(a) The average $P-A T_{8}$ time interval was $0.060 \mathrm{sec}$. in 16 cases. In a previously reported case of a child 8 years of age with tetralogy of Fallot, a value of $0.055 \mathrm{sec}$. was found, Cournand et al., 1946. The question arose as to whether the $\mathbf{P}-\mathbf{A T}_{\mathbf{s}}$ time varies with the age of the subjects. In general it was found that the younger the child the shorter the P-AT time although the correlation did not appear to be extremely close. In Fig. 4 is illustrated the $\mathbf{P}-\mathbf{A T}_{\mathrm{s}}$ time interval in a child of 3 . In general, the nature of the congenital disease did not appear to exert a great influence on this time interval. In two 
TABLE II

Previously Published Values for the Time Interval Between the Beginning of Q and the Onset of Arterial Pressure Rise (IN Seconds)

\begin{tabular}{|c|c|c|c|c|c|}
\hline Author & & & Interval studied & Range & Average \\
\hline $\begin{array}{l}\text { Nichol (1933) } \\
\text { Wolferth et al. (1935) } \\
\text { Katz et al. }(1935) \quad \ldots \\
\text { Battro et al. (1936) } \\
\text { Castex et al. }(1941) \\
\text { Kossmann } \text { et al. (1947) } \\
\text { Present study (1948).. }\end{array}$ & $\begin{array}{l}\cdots \\
\cdots \\
\cdots \\
\cdots \\
\cdots \\
\cdots\end{array}$ & $\begin{array}{l}\cdots \\
\cdots \\
\cdots \\
\cdots \\
\cdots\end{array}$ & $\begin{array}{l}Q \text { to rise of pressure in subclavian artery } \\
Q \text { to rise of pressure in carotid artery } \\
Q \text { to rise of pressure in subclavian artery } \\
Q \text { to rise of pressure in carotid artery } \\
Q \text { to rise of pressure in carotid artery } \\
Q \text { to rise of pressure in carotid artery } \\
Q \text { to rise of pressure in brachial artery }\end{array}$ & $\begin{array}{l}0 \cdot 119-0 \cdot 166 \\
0 \cdot 090-0 \cdot 150 \\
0 \cdot 100-0 \cdot 160 \\
0 \cdot 060-0 \cdot 120 \\
0 \cdot 080-0 \cdot 160 \\
0 \cdot 131-0 \cdot 148 \\
0 \cdot 140-0 \cdot 190\end{array}$ & $\begin{array}{l}0 \cdot 135 \\
0 \cdot 111 \\
0 \cdot 120 \\
-\overline{0} \\
0 \cdot 120 \\
0 \cdot 139 \\
0 \cdot 160\end{array}$ \\
\hline
\end{tabular}

TABLE III

Relationship Between Electrical and Mechanical Events in Children with Congenital HEART DISEASE

\begin{tabular}{|c|c|c|c|c|c|c|c|}
\hline Heart rate per minute & .. & .. & . & .. & Average of 23 cases & 109 & - \\
\hline PR interval, sec. .. & . & $\cdots$ & $\cdots$ & .. & Average of 23 cases & $0 \cdot 140$ & - \\
\hline QRS interval, sec. & .. & .. & .. & .. & Average of 23 cases & 0.060 & \\
\hline Q-BAs interval, sec. & .. & .. & .. & .. & Average of 23 cases & $0 \cdot 150$ & $0 \cdot 140-0 \cdot 190$ \\
\hline P-Ats interval, sec. & . & .. & .. & .. & Average of 16 cases & 0.060 & $0.030-0.090$ \\
\hline Q-RV $\mathbf{V}_{\text {s }}$ interval, sec. & .. & . & . & .. & $\begin{array}{l}\text { Average of } 23 \text { cases } \\
\text { Average of } 12 \text { cases* }\end{array}$ & $\begin{array}{l}0.058 \\
0.056\end{array}$ & $0 \cdot 040-0 \cdot 100$ \\
\hline $\begin{array}{l}\text { Q-PAs interval, sec. } \\
\text { End diastolic pressure in }\end{array}$ & $\cdots$ & .. & & & Average of 12 cases* & 0.079 & $0.050-0 \cdot 110$ \\
\hline Right ventricle, $\mathrm{mm}$ & 7. $\mathrm{Hg}_{\text {. }}$ & & .. & .. & Average of 12 cases* & $5 \cdot 0$ & - \\
\hline Duration of isometric cor & $\begin{array}{l}\mathrm{mm} . \mathbf{H} \\
\text { ntractic }\end{array}$ & on of & right ve & ntricle, sec. & Average of 12 cases* & $\begin{array}{c}18 \cdot 0 \\
0.023\end{array}$ & $0.010-0.030$ \\
\hline
\end{tabular}

* The same 12 cases were used to obtain these values.

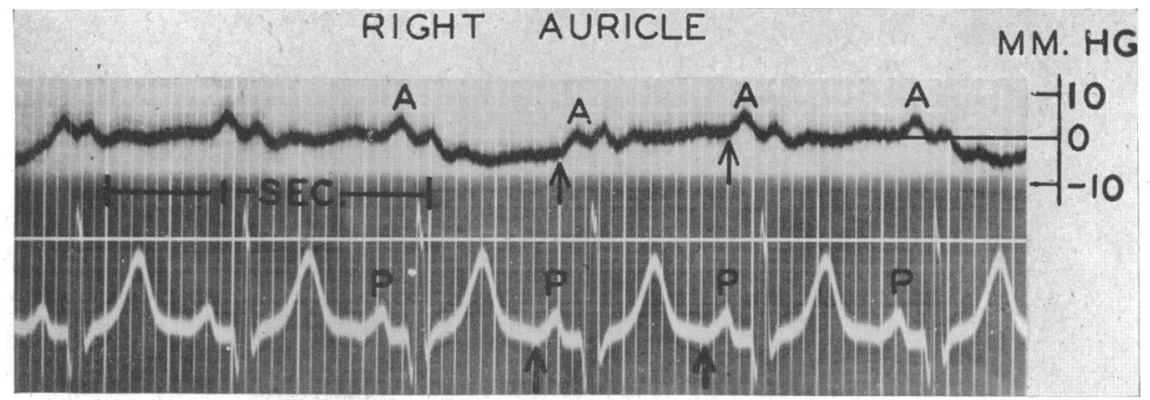

FIG. 4.-Record illustrating electrical-mechanical time intervals in a child of 3 years with congenital heart disease.

From top to bottom, blood pressure tracings in the right atrium and electrocardiogram lead II. The electrocardiographic standardization is 1 millivolt $=2$ centimetres.

cases of interauricular septal defect the $\mathbf{P}-\mathrm{AT}_{\mathrm{s}}$ times in the right and in the left auricles were identical, i.e. $0 \cdot 060 \mathrm{sec}$.

(b) The average $Q-R V_{s}$ time interval, extending from the initial deflection of the QRS complex to the beginning of the right ventricular systole was 0.058 sec. in 23 cases. No significant relationship could be found between this time interval and the nature of the defect or the age of the subject. It is, however, important to note that in all types of congenital defects, even in the cases with hypertrophy and dilatation of the right ventricle, the duration of $\mathrm{Q}-\mathrm{RV}_{\mathrm{s}}$ was never greater than in normal adults. In one case of interventricular septal defect the 
Q- $\mathbf{V}_{\mathbf{s}}$ time intervals were the same in the right and in the left ventricle, i.e. $0.070 \mathrm{sec}$. (Fig. 5).

For lack of knowledge of the exact onset of the initial electrical deflection corresponding to activation in each of the four separate chambers of the heart, no conclusion can be drawn from the figures given in this and the previous section as to the spread of excitation and beginning of contraction in each chamber.

(c) The average $Q-P A_{s}$ time interval was $0.079 \mathrm{sec}$. in 12 cases. The difference between this figure and the $\mathrm{Q}-\mathrm{RV}$ s time interval in these 12 cases, represented an average duration of isometric contraction in the right ventricle of $0.023 \mathrm{sec}$., with a range of 0.010 to $0.030 \mathrm{sec}$. Since the average pressure values at the end of diastole in the right ventricle and in the pulmonary artery were $5 \mathrm{~mm} . \mathrm{Hg}$. and $18 \mathrm{~mm}$. $\mathrm{Hg}$. respectively, this time interval $(0.023$ sec.) was required to raise the pressure in the right ventricle by $13 \mathrm{~mm}$. $\mathrm{Hg}$. This increase in the duration of isometric contraction was therefore due to hypertension in the lesser circulation. In a case of patent ductus arteriosus studied before and after ligation a change in the duration of isometric contraction was noted. As seen in Table IV, 0.030 sec. was required to raise the pressure in the right ventricle $36 \mathrm{~mm}$. $\mathrm{Hg}$. before operation. After ligation the duration of isometric contraction was reduced to $0.010 \mathrm{sec}$. for a pressure rise in the right ventricle from 1 to $5 \mathrm{~mm}$. $\mathrm{Hg}$.

(d) The average $Q-B A_{s}$ time was $0.150 \mathrm{sec}$. in 23 cases. This figure is almost identical with that found in adults, although the distance between the heart and the peripheral artery is obviously less. If one assumes that the time of isometric contraction in the left ventricle is approximately the same in children as in adults, then the pulse wave velocity must be much slower in children. This finding is not unexpected because of the greater deformability of the arterial walls in young subjects.

\section{Relationship Between Electrical and Mecha- NiCal Events in Adult Patients with Cardio- VASCULAR DISEASE}

\section{(a) Normal Sinus Rhythm with no Conduction Abnormalities}

In Table $\mathrm{V}$ will be found the average figures relating electrical and mechanical events in a group

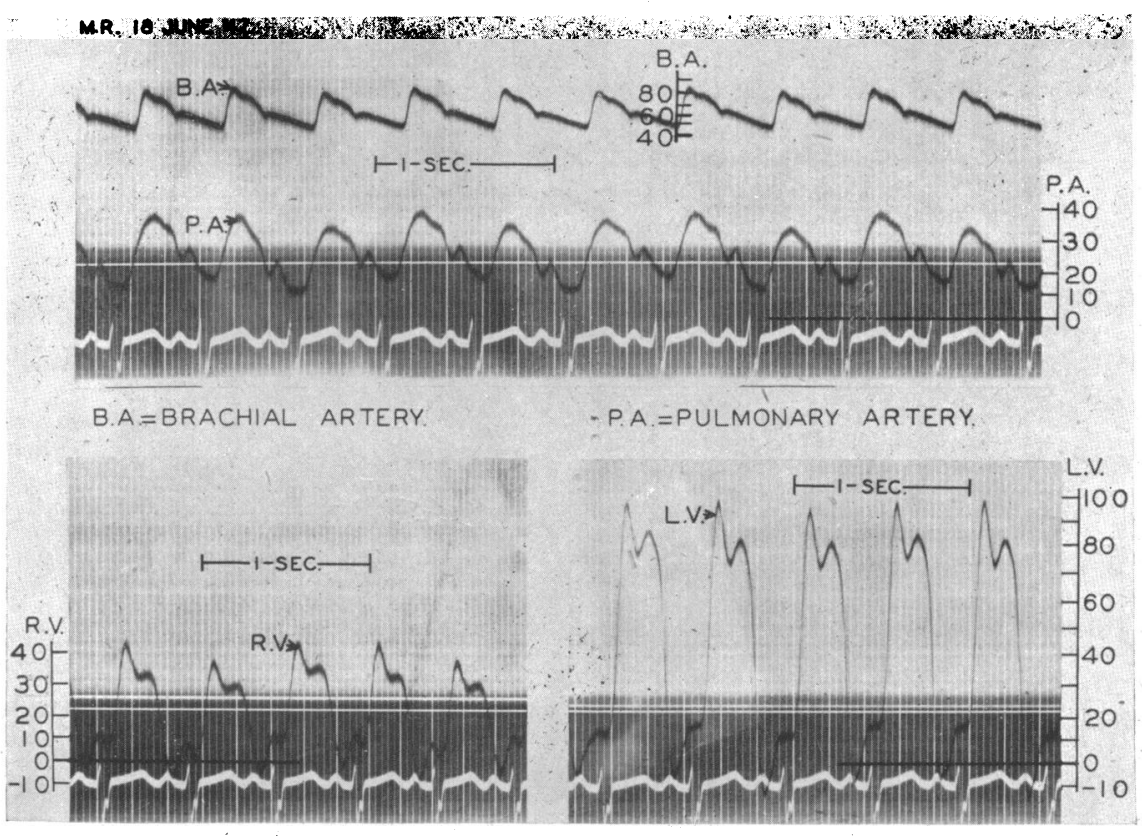

FIG. 5.-Records illustrating electrical-mechanical events in a case with interventricular septal defect.

Upper row from top to bottom, blood pressure tracings in the brachial artery (B.A.) and the pulmonary artery (P.A.). Lower row: at left, blood pressure tracing in the right ventricle (R.V.), at right, blood pressure tracing in the left ventricle (L.V.). Note that the tracings in the ventricles may show some evidence of overshooting. $Q-R V_{s}=0.070 \mathrm{sec}$. Q-PAs $=0.080 \mathrm{sec}$. Q-LV $\mathrm{LV}_{s}=0.070 \mathrm{sec} . \quad \mathrm{Q}-\mathrm{BA}_{s}=0.150 \mathrm{sec}$. R.V. = Right ventricle. $\quad$ L.V. $=$ Left ventricle.

All pressures in mm. Hg. Electrocardiogram, lead II. 
TABLE IV

Relationship Between Electrical and Mechanical Events Before and After ligation in a Case of Patent Ductus arteriosus

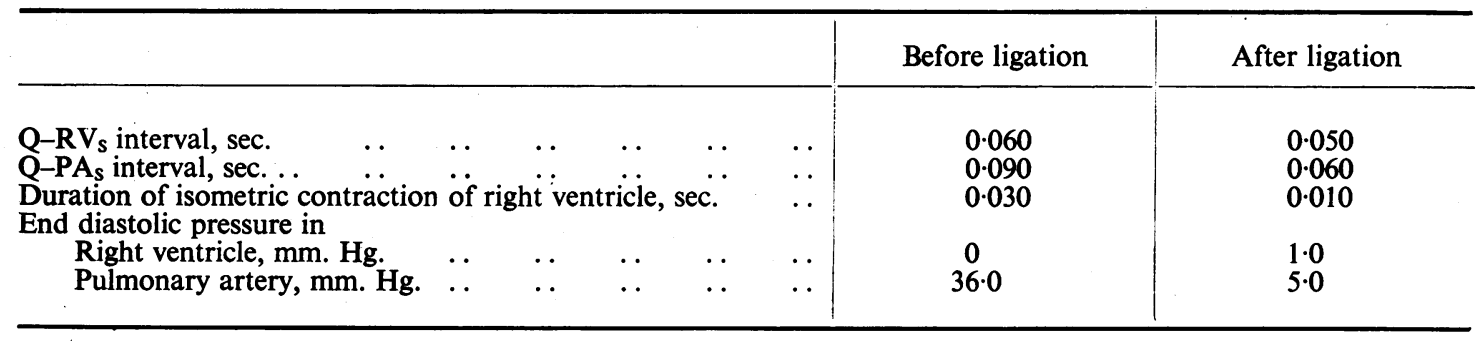

TABLE V

Relationship Between Electrical and Mechanical Events in Adults with Cardiovaścular Disease

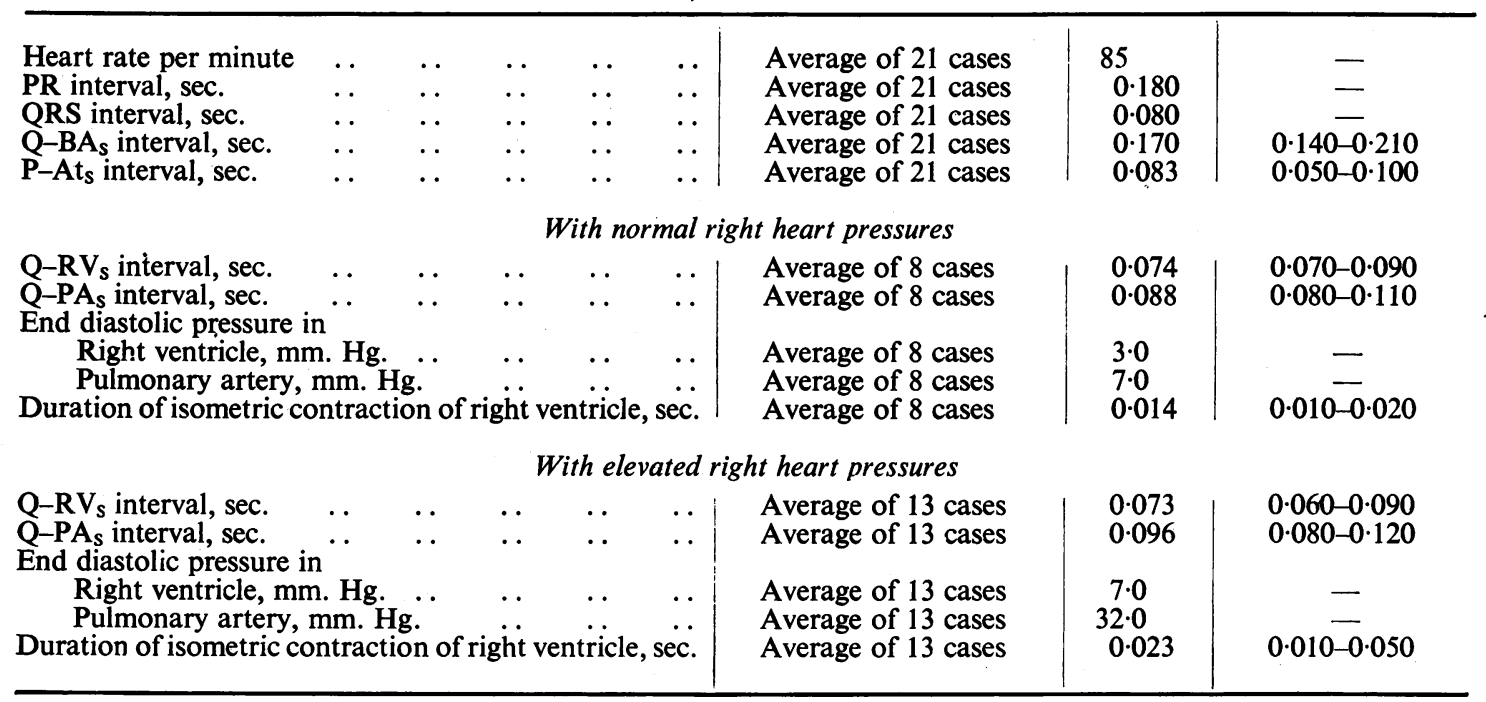

of 21 patients with various types of cardiovascular disease including congenital, rheumatic, hypertensive, arteriosclerotic, and cor pulmonale.

In all these patients the $P-A_{s}, Q-R V_{s}$, and $Q-B A_{s}$ time intervals were approximately the same as in normal adults regardless of the presence or absence of cardiac failure.

The $\mathbf{Q}-\mathbf{P A}_{\mathrm{s}}$ time interval studied in 8 cases of heart disease with normal right heart and pulmonary artery pressures (without evidence of congestive failure) was identical with the figure found in normal adults. In 13 patients with elevated right heart and pulmonary artery pressures and evidence of congestive failure, the average $\mathbf{Q}-\mathbf{P A}_{\mathrm{s}}$ time interval was slightly prolonged although the range did not differ greatly from the normals.

The average duration of the isometric contraction of the right ventricle in cardiacs with normal right heart pressures was $0.014 \mathrm{sec}$., essentially a normal figure. This interval was required to raise the pres- sure in the right ventricle from an average of 3 to 7 $\mathrm{mm}$. Hg. In the patients with congestive failure an average of $0.023 \mathrm{sec}$. was required to raise the pressure from 7 to $32 \mathrm{~mm}$. Hg. a difference of $25 \mathrm{~mm}$. This figure falls within the normal variation but the range was greater, and in some cases with hypertension of the lesser circulation, isometric contraction was markedly prolonged. As can be seen in Fig. 10 (see p. 12), there appears to be a trend of correlation between the duration of isometric contraction of the right ventricle and the magnitude of the pressure difference between the end diastolic levels of the right ventricle and the pulmonary artery.

(b) Abnormalities of Rhythm, Conduction, and Contraction. (1) Auricular premature contractions

Auricular premature beats were observed in three patients. In two, pressures were recorded in the right auricle, and in the third in the right auricle and right ventricle. A representative tracing is seen in 
Fig. 2 (see p. 3). There was no demonstrable difference in the $\mathbf{P}-\mathrm{At}_{\mathrm{s}}, \mathrm{Q}-\mathrm{RV}_{s}$, and $\mathrm{Q}-\mathrm{BA}_{\mathrm{s}}$ time intervals in the premature beat as compared to the sinus beat. It should be noted that in all these cases the degree of prematurity was not marked.

\section{(2) Ventricular premature contractions}

The data that form the basis of this analysis were accumulated at random. It is therefore obvious that a systematic study, using more complete electrocardiographic data (conventional and endocardial leads), is required to confirm and amplify the findings reported here. In particular the problem of induced right ventricular premature contractions should be greatly clarified by a well planned study.

In this report emphasis will be placed only upon the following points: (a) asynchronism of the two ventricles, (b) nature and character of auricular events during the premature ventricular contractions, (c) relationship between premature contraction and arterial systolic rise.

(a) Ventricular asynchronism and its relationship to the site of origin of the premature ventricular contractions. The type of ventricular asynchronism produced by premature ventricular contractions can be identified by examination of mechanical events recorded simultaneously on both sides of the heart. A prolongation of the $\mathrm{Q}-\mathrm{RV}_{\mathrm{s}}$ time alone suggests a delay in contraction of the right ventricle, while prolongation of the $\mathrm{Q}-\mathrm{BA}_{\mathrm{s}}$ time points to a delay in left ventricular contraction.

However, in order to compare the Q-BAs time interval of the normal beat and the premature contraction, it was necessary to read the $\mathbf{Q}-\mathbf{B A}_{\mathbf{s}}$ times at the same pressure levels. Since the diastolic

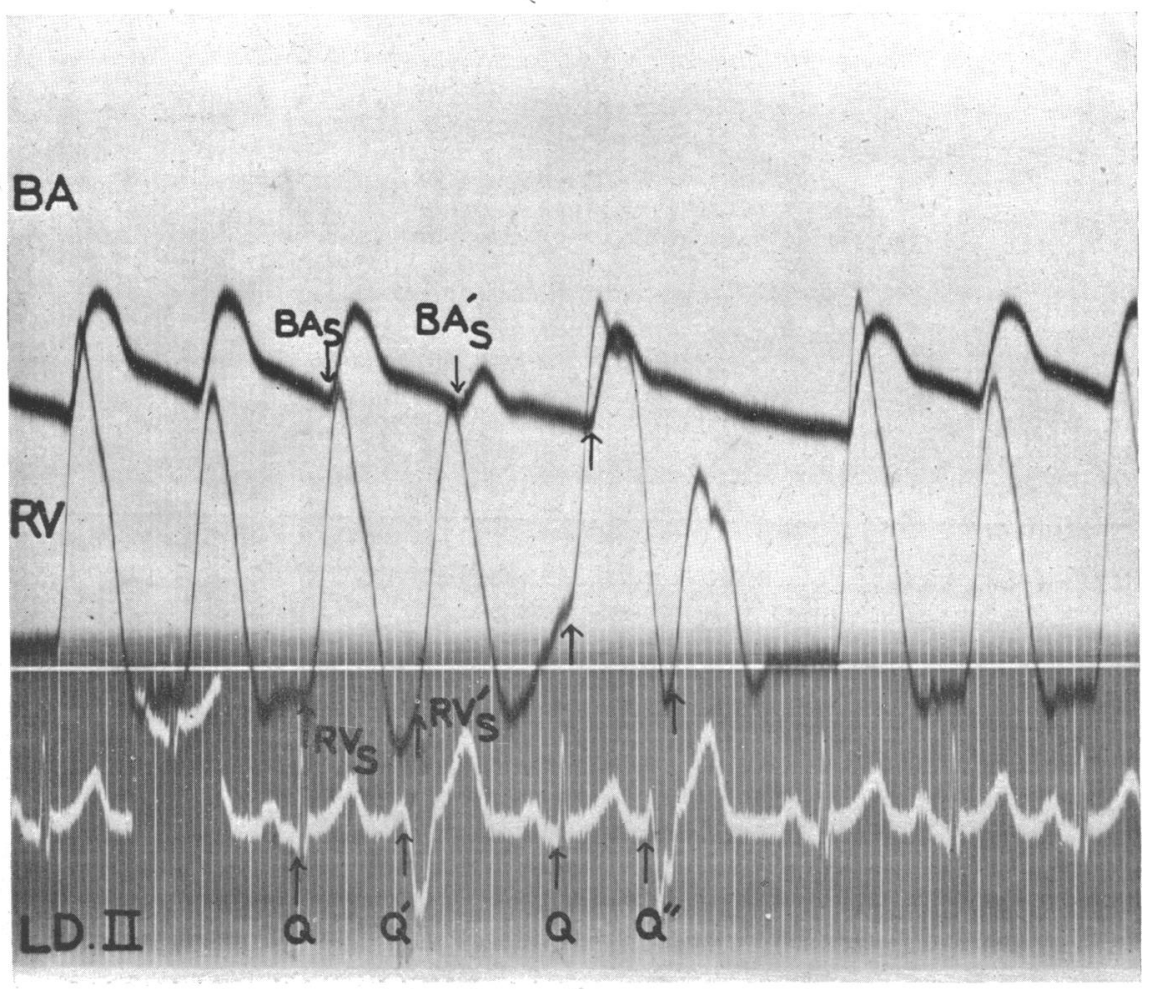

FIG. 6.-Record illustrating electrical-mechanical events in a case with ventricular premature contractions.

From top to bottom, blood pressure tracings in the brachial artery (B.A.), the right ventricle (R.V.), and electrocardiogram lead II. $Q^{\prime}$ and $Q^{\prime \prime}$ correspond to premature contractions.

$\mathrm{Q}^{-} \mathrm{BA}_{\mathrm{s}}=0.130 \mathrm{sec} . \quad \mathrm{Q}-\mathrm{RV}_{\mathrm{s}}=0.060 \mathrm{sec} . \mathrm{Q}^{\prime}-\mathrm{BA}_{\mathrm{s}}=0.210 \mathrm{sec} . \mathrm{Q}^{\prime}-\mathrm{RV}_{\mathrm{s}}=0.060 \mathrm{sec}$

$$
\begin{aligned}
& Q-R V_{s}=0.060 \mathrm{sec} . \\
& Q-Q^{\prime}=0.44 \mathrm{sec} .
\end{aligned}
$$

Note that $Q^{\prime \prime}$ is not followed by demonstrable pulse wave in the brachial artery and corresponds to a low pressure rise in the right ventricle. 
pressure in the aorta will be higher the earlier the premature contraction, it was arbitrarily decided to read the Q-BA time for the normal beat at the initial pressure level of the premature beat.

The majority of ventricular premature beats studied, showed as the striking characteristic, a lengthening of the Q-BA time (average of 9 cases, $0.227 \mathrm{sec}$., range 0.180 to $0.270 \mathrm{sec}$.) while the $Q-R V_{s}$ time remained normal (average of 9 cases, $0.074 \mathrm{sec}$., range 0.060 to $0.100 \mathrm{sec}$.). An illustrative example is shown in Fig. 6.

However, in one patient in whom numerous premature beats were observed, the $\mathrm{Q}-\mathrm{BA}_{s}$ time intervals in the sinus and premature beats were respectively 0.140 and $0.150 \mathrm{sec}$. In contrast, the $\mathrm{Q}-\mathrm{RV}_{\mathrm{s}}$ time of the sinus beats varied from 0.060 to $0.070 \mathrm{sec}$. while the $\mathbf{Q}-\mathbf{R V} \mathrm{V}_{\mathrm{s}}$ times of the premature beats were 0.070 to $0.100 \mathrm{sec}$.

In summary, the ventricular asynchronism found suggests that there was a delay in left ventricular contraction in the first group of 9 patients, whereas in one case the observations point to a delay in right ventricular contraction. Whether the delay was due to abnormalities of contraction or spread of excitation or both, is a matter of conjecture.

The relationship between the type of ventricular asynchronism and the site of origin of the ventricular premature beats is of considerable interest. In the first group of 9 patients the site of origin of most of these spontaneous premature contractions could not be identified since the majority of pressure recordings were made simultaneously with lead II of the electrocardiograph. However, the type of ventricular asynchronism suggests a right ventricular origin for these beats.

In the single patient previously discussed, the type of ventricular asynchronism suggests a left ventricular origin for all the premature beats. However, the successive premature contractions as recorded on lead I were of such different electrical configurations as to suggest both right and left ventricular origins. In addition, in a second case a similar situation was found. In this instance two isolated premature beats with QRS deflections in opposite directions were recorded in lead I (Fig. 7). It is seen that while the normal beat shows a $\mathbf{Q}-\mathrm{RV}_{\mathbf{s}}$ time interval of $0.070 \mathrm{sec}$. the same interval measures $0.170 \mathrm{sec}$. in the first premature beat and $0.150 \mathrm{sec}$. in the second. There was no pressure wave in the brachial artery tracing corresponding to the ectopic beats, indicating absence of ejection into the aorta and, therefore, no information as to the events in the left ventricle could be obtained.

It is obvious from the two cases just cited that it is difficult to interpret the relationship between electrical configuration of the premature contractions and the mechanical events, since different electrical patterns gave the same type of ventricular asynchronism.

In the only investigations so far reported in man relating to this type of asynchronism, Castex, Battro, and Gonzales (1941) have shown that in premature

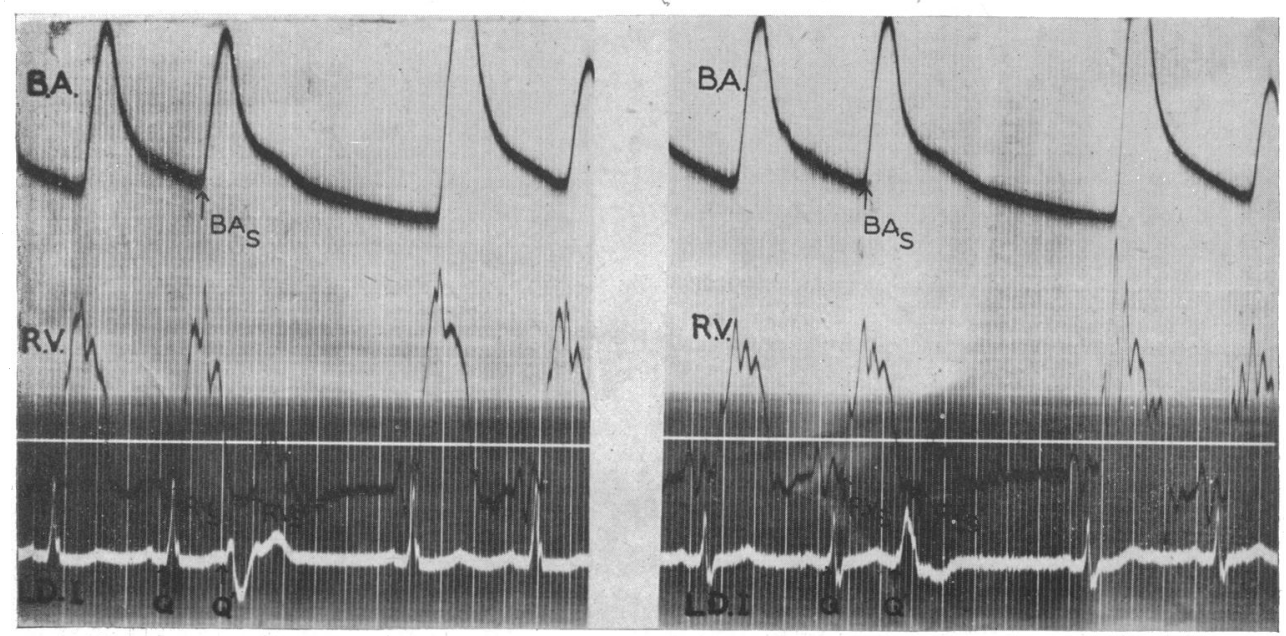

Fig. 7.-Records illustrating electrical-mechanical events in a case with ventricular premature contractions characterized by different electrical patterns.

From top to bottom, blood pressure tracings in the brachial artery (B.A.), the right ventricle (R.V.), and electrocardiogram lead I.

In the electrocardiogram to the right an $\mathrm{S}$ wave has appeared, indicating right bundle branch block induced by quinidine. Ventricular tracings show many artifacts, but the early systolic pressure rise can be defined. 
beats there is a very significant increase in the time interval between the onset of the QRS complex and the beginning of pressure rise in the subclavian artery. In 76 normal subjects the time interval averaged $0.120 \mathrm{sec}$., while in 10 cases of right ventricular premature contractions, it averaged 0.220 sec. An unexpected finding was the prolongation of the time interval between $Q$ and the pressure rise in the subclavian artery in 13 cases of left ventricular premature contractions.

(b) Nature and character of auricular events during the premature ventricular contractions. In 6 cases of ventricular premature beats, tracings of right auricular pressure waves showed a rise in pressure, $\mathbf{A}^{\prime}$, occurring during and immediately following ectopic ventricular complexes. This is in contrast to the usual drop in pressure accompanying the descent of the base at the onset of ventricular systole. Examples of such tracings are seen in Fig. 8 and 9. The question arises as to whether these pressure waves, $\mathbf{A}^{\prime}$, were related to tricuspid insufficiency, bulging of the valve during ventricular isometric contraction, or to auricular systole of sinus or retrograde origin. In some instances a $P$ wave could be detected in the S-T segment of the premature beats. These $P$ waves preceded by the usual $P-A_{S}$ time interval, the auricular pressure rise, $A^{\prime}$. In other instances no auricular deflection could be identified within the QRS complex or S-T segment. In both instances the time interval separating the previous auricular systole and $\mathrm{A}^{\prime}$ was identical with the distance between the normal auricular systoles regardless of the time at which the ventricular premature contraction appeared. This indicates that $\mathrm{A}^{\prime}$ in these instances is the result of a normal auricular systole.

These findings are in agreement with observations of Lewis (1925) on premature beats as illustrated in his monograph (Fig. 182, page 212). In summary, it can be assumed that even when a premature ventricular beat occurs, the spread of stimulation from the sinus node may take place undisturbed and initiate a normal auricular contraction.

(c) Relationship between ventricular ejection and degree of prematurity. It is a clinically established fact that some premature beats are followed by ejection of blood into the aorta, while some are not. With simultaneous recordings of the electrocardiogram and pulse waves in brachial artery and pulmonary artery, it is possible to obtain information concerning the shortest time interval between a normal sinus and a premature beat $\left(Q^{-}-Q^{\prime}\right.$ interval) that gives rise to ejection of blood from the right and left ventricles, and the relation between this time interval and the heart rate. Table VI and Fig. 11 give data obtained in 9 patients concerning these problems. All the tracings showed several premature contractions occurring at various intervals after the sinus beats. In three of these cases pulmonary artery tracings were also available. It is seen that the shortest time interval between a sinus beat and a premature beat followed by left or right ventricular ejection varied with the rate and ranged between

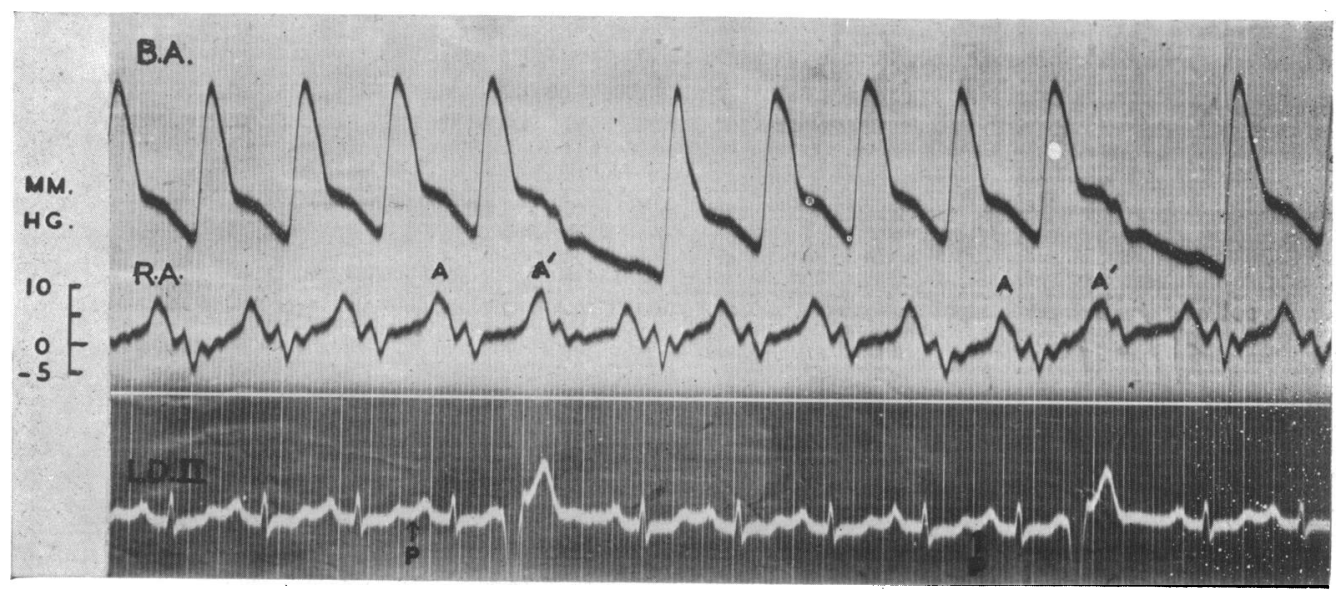
Fig. 8.- Record illustrating electrical-mechanical events in the atrium in a case with ventricular prem-
ature contractions.

From top to bottom, blood pressure tracings in the brachial artery (B.A.), right atrium (R.A.), and electrocardiogram lead II.

Note that the interval $A-A^{\prime}$ is equal to the normal auricular cycle time indicating that the sinus rhythm is undisturbed by premature contractions. 


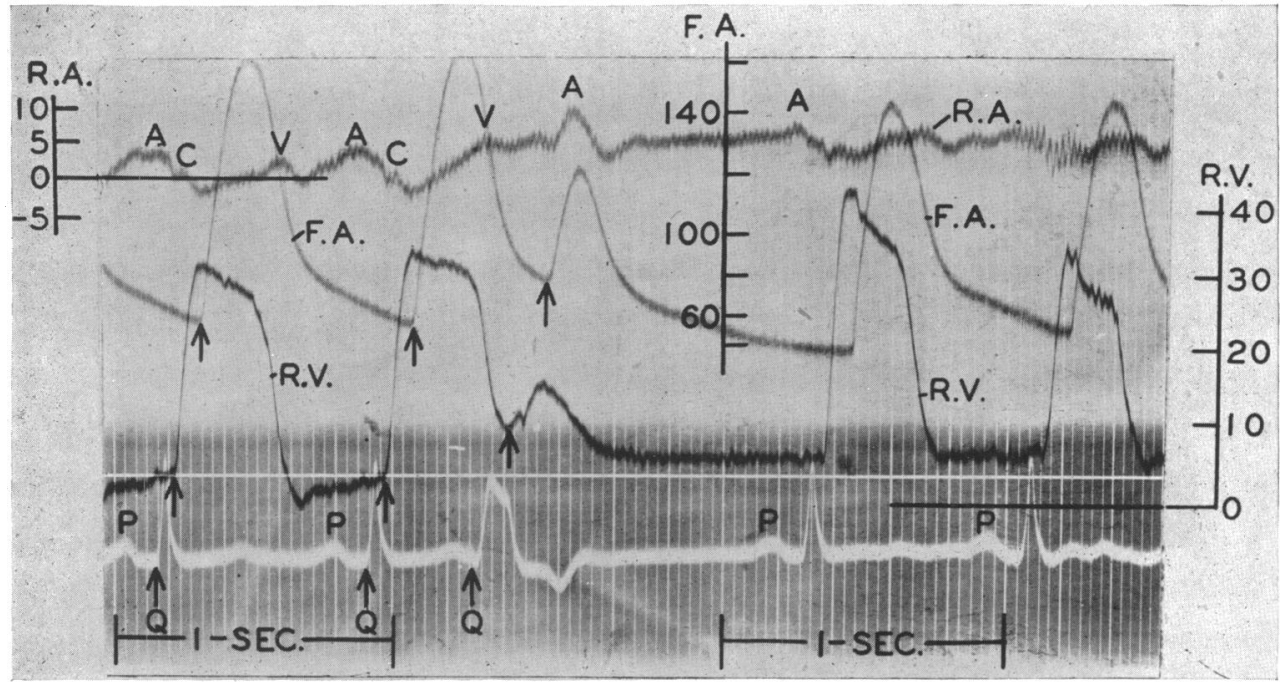

FIG. 9.-Record illustrating electrical-mechanical events in a case with ventricular premature contractions.

From top to bottom, blood pressure tracings from the right atrium (R.A.), the femoral artery (F.A.), the right ventricle (R.V.), and electrocardiogram lead II. For discussion see text. The blood pressure tracings in the right atrium and right ventricle were taken with a double lumen catheter.

Note that the brachial artery tracing shows left ventricular output following the premature contraction and that the corresponding right ventricular pressure curve starts during isometric relaxation. This is strong evidence in favour of the presence of residual blood at the time of the premature contraction.

F.A. $=$ Femoral artery. $\quad$ R.V. = Right ventricle. R.A. = Right auricle. Electrocardiogram, lead II. A-C-V waves marked on R. Aur. All pressures in $\mathrm{mm}$. Hg.

TABLE VI

Relationship Between Heart Rate and the Minimum Ejection Time in the Brachial and Pulmonary Arteries in Nine Cases with Ventricular Premature Beats

\begin{tabular}{|c|c|c|c|c|}
\hline \multirow{2}{*}{$\begin{array}{c}\text { Case } \\
\text { no. }\end{array}$} & \multirow{2}{*}{$\begin{array}{l}\text { Duration of the normal } \\
\text { cycle, sec. }\end{array}$} & \multirow{2}{*}{$\begin{array}{l}\text { Heart rate } \\
\text { per minute }\end{array}$} & \multicolumn{2}{|c|}{ Shortest $\mathrm{Q}-\mathrm{Q}^{\prime *}$ interval followed by ejection in the: } \\
\hline & & & Brachial artery, sec. & Pulmonary artery, sec. \\
\hline $\begin{array}{l}317 \\
315 \\
348 \\
345 \\
316 \\
350 \\
306 \\
313 \\
320\end{array}$ & $\begin{array}{l}0.460 \\
0.540 \\
0.680 \\
0.720 \\
0.760 \\
0.780 \\
0.780 \\
0.920 \\
1.040\end{array}$ & $\begin{array}{r}130 \\
111 \\
88 \\
83 \\
79 \\
78 \\
78 \\
65 \\
58\end{array}$ & $\begin{array}{l}0.340 \\
0.400 \\
0.440 \\
0.410 \\
0.510 \\
0.480 \\
0.450 \\
0.500 \\
0.640\end{array}$ & $\begin{array}{c}0.340 \\
\overline{0} \\
0.440 \\
\overline{0.480} \\
- \\
- \\
-\end{array}$ \\
\hline
\end{tabular}

* $Q-Q^{\prime}$ interval is the time interval between the beginning of the QRS of the sinus beat and the beginning of the QRS of the ventricular premature beat.

$0.340 \mathrm{sec}$. at 130 beats a minute and $0.640 \mathrm{sec}$. at 58 beats a minute. The remarkable straight line relationship of all intermediate points is, well illustrated in the graph (Fig. 11).

In summary, at a rapid rate an early premature beat was followed by ejection of blood into the aorta and pulmonary artery; whereas, at a slower rate, a ventricular contraction with the same degree of prematurity did not produce a pressure rise in the arterial tracings. These observations can best be explained by the more rapid early diastolic filling of the heart at faster rates. 


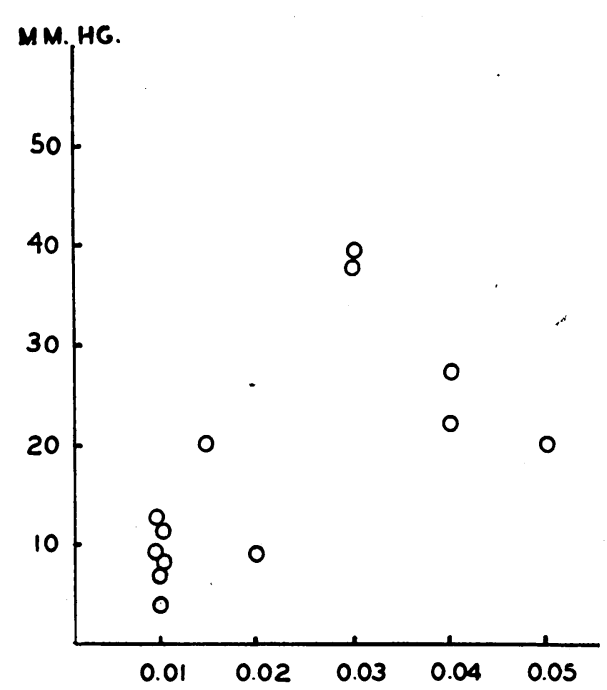

FIG. 10.-Correlation between the duration of isometric contraction and the corresponding pressure rise in the right ventricle in thirteen subjects including normal cases and cases with cardiac failure. The vertical scale shows the end diastolic pressure difference between the right ventricle and the pulmonary artery. The horizontal scale shows the isometric contraction time in seconds. For discussion see text.

\section{(3) Auricular Fibrillation}

A study of the relationship between cycle length and $\mathrm{Q}-\mathrm{RV} \mathrm{V}_{\boldsymbol{s}}$ and $\mathrm{Q}-\mathrm{BA}_{\boldsymbol{s}}$ time intervals was made in three cases of arteriosclerotic heart disease with chronic auricular fibrillation. Significant variations as large as $\mathbf{0 . 0 7 0} \mathrm{sec}$. were found in the $\mathrm{Q}-\mathrm{RV}_{\mathrm{s}}$ and

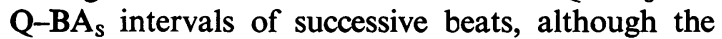
QRS complexes had essentially the same configuration and duration. No constant relationship was found between cycle length and these variations in the electrical-mechanical time intervals. In addition, the $\mathbf{Q}-\mathbf{R V}_{\mathrm{s}}$ and $\mathbf{Q}-\mathbf{B A}_{\mathrm{s}}$ intervals of the same beat did not vary to the same degree, as illustrated in Fig. 12. These findings suggest that, besides the complete arrhythmia, disturbances of the contraction mechanism of both ventricles were present.

\section{(4) Auricular Flutter}

Two cases of auricular flutter were studied. In one of the cases observations were made on the $\mathbf{P}-\mathrm{AT}_{\mathrm{s}}$ time during a period with pure flutter and a 4:1 A-V response. The electrocardiogram and right auricular tracings are shown in Fig. 13 and demonstrate the regular sequence of electrical and mechanical events. The duration of the $\mathrm{P}-\mathrm{AT}_{s}$ time of each auricular systole was $0.070 \mathrm{sec}$., a figure slightly lower than the normal mean, but within the

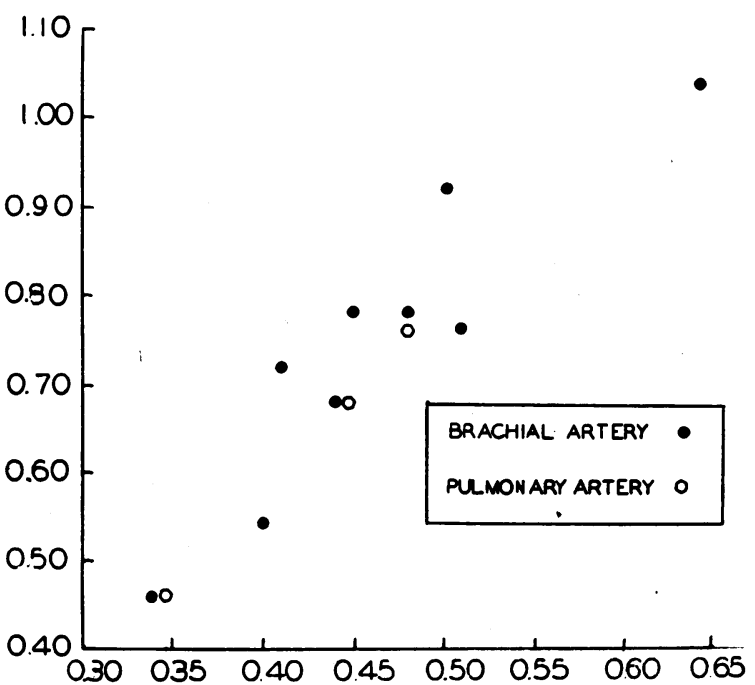

FIG. 11.-Correlation between heart rate and the shortest time interval between a normal beat and a premature contraction resulting in ejection of blood into the aorta or pulmonary artery. The horizontal scale shows the $Q-Q^{\prime}$ interval in seconds: the vertical scale shows the duration of the normal cycle in seconds.

normal range of variation. In this and a second case, varying degrees of block were also observed. Pressure tracings in the right auricle, right ventricle, and brachial artery were recorded and are illustrated in Fig. 14. It is seen that the $3: 1$ cycle with its longer ventricular diastolic filling period was followed by a larger pressure rise in the brachial artery and right ventricle than was the $2: 1$ cycle with its shorter filling period. The auricular pressure tracings were not influenced by the degree of block, while the brachial artery and right ventricular pressures were dependent on the time at which the QRS fell in relation to isometric relaxation. In addition, it was found that the Q- $\mathrm{BA}_{\mathrm{s}}$ time of the weak beat was longer by $0.020 \mathrm{sec}$. than the $\mathrm{Q}-\mathrm{BA}_{\mathrm{s}}$ time of the strong beat, if both beats were read at the same pressure levels. This suggests that the duration of isometric contraction was prolonged following poor filling of the ventricles. Similar observations regarding the influence of the varying $A-V$ response upon the brachial artery pressure are seen in Fig. 15 which illustrates a case of auricular flutter with successive $3: 1,2: 1,1: 1 \mathrm{~A}-\mathrm{V}$ ratio.

\section{(5) Heart Block}

Nine cases with different types of heart block were studied; two cases of complete heart block with idio- 


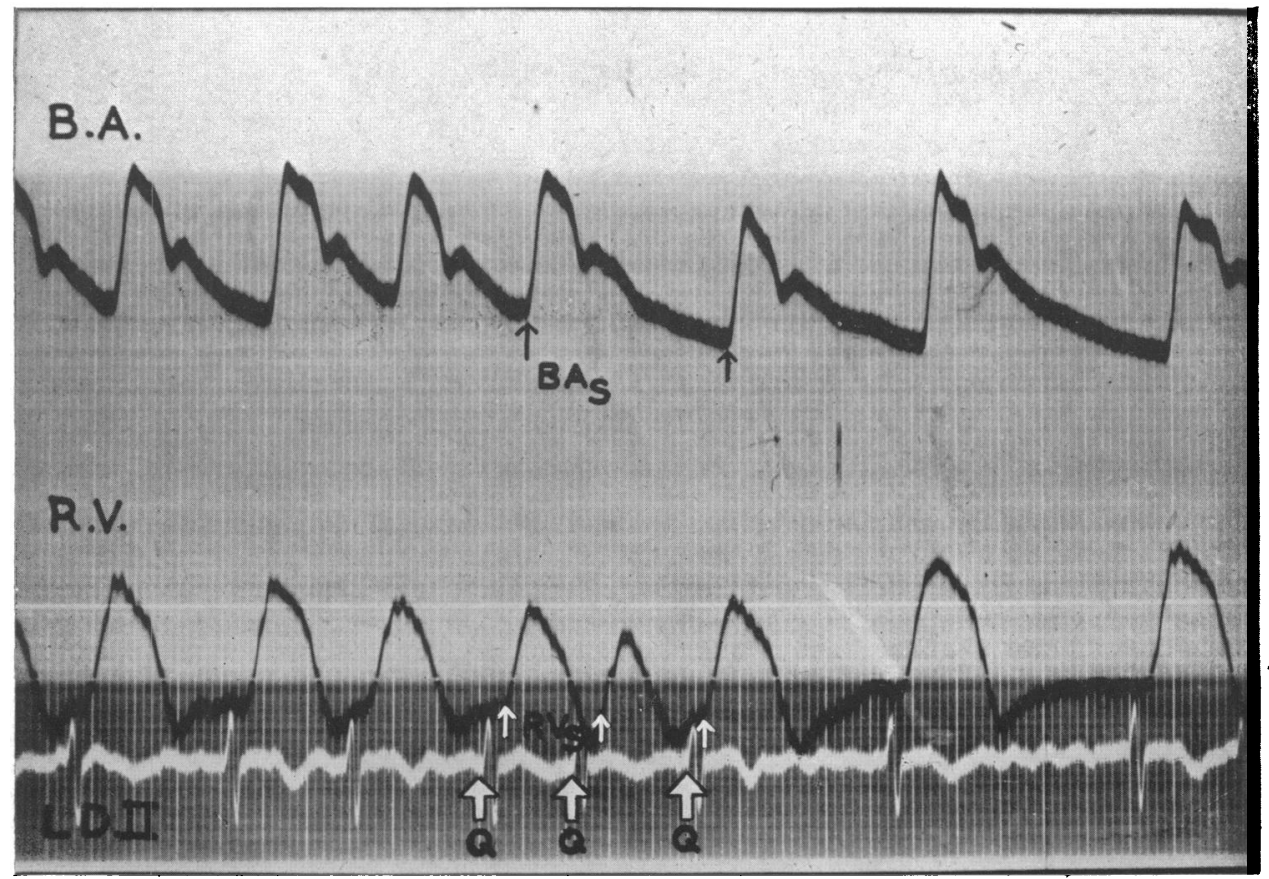

FIG. 12.-Record illustrating electrical-mechanical events in a case of auricular fibrillation.

From top to bottom, blood pressure tracings in the brachial artery (B.A.), right ventricle (R.V.), and electrocardiogram lead II.

In the three beats indicated by arrows the successive $Q-R V_{s}$ and Q-BAs times were: first beat, $Q-R V_{s}=0.110$ sec. and $Q-B A_{s}=0.190$ sec.; second beat, $Q-R V_{s}=0.110$ sec. and $\mathrm{Q}-\mathrm{BA} \mathrm{A}_{s}$ not measurable; third beat, $\mathrm{Q}-\mathrm{RV}_{\mathrm{s}}=0.070 \mathrm{sec}$. and $\mathrm{Q}-\mathrm{BA} s=0.170 \mathrm{sec}$.

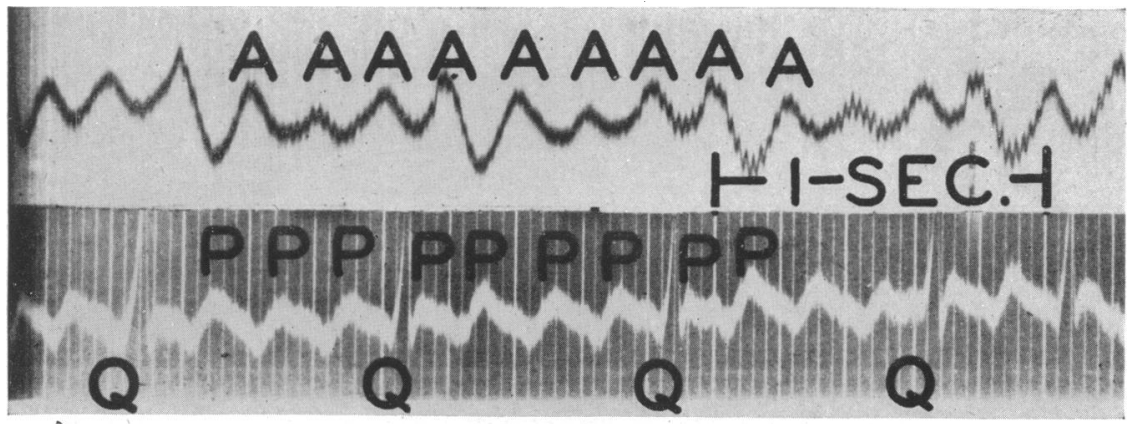

FIG. 13.-Auricular flutter. Record illustrating electrical-mechanical events in a case with a 4:1 A-V response.

From top to bottom, right atrial blood pressure tracings and electrocardiogram lead II. For discussion see text.

ventricular rhythm originating in the His bundle, one case of incomplete A-V heart block, two cases of left bundle branch block, two cases of right bundle branch block, and two cases of right bundle branch block with 2:1 A-V heart block, one of which showed runs of complete heart block. (a) Complete heart block. The two cases with complete heart block had P waves and QRS complexes of normal duration. The data relating to the duration of the time intervals between electrical and mechanical events will be found in Table VII. As was to be expected, the P-AT , the $\mathrm{Q}-\mathrm{RV}$, and the 


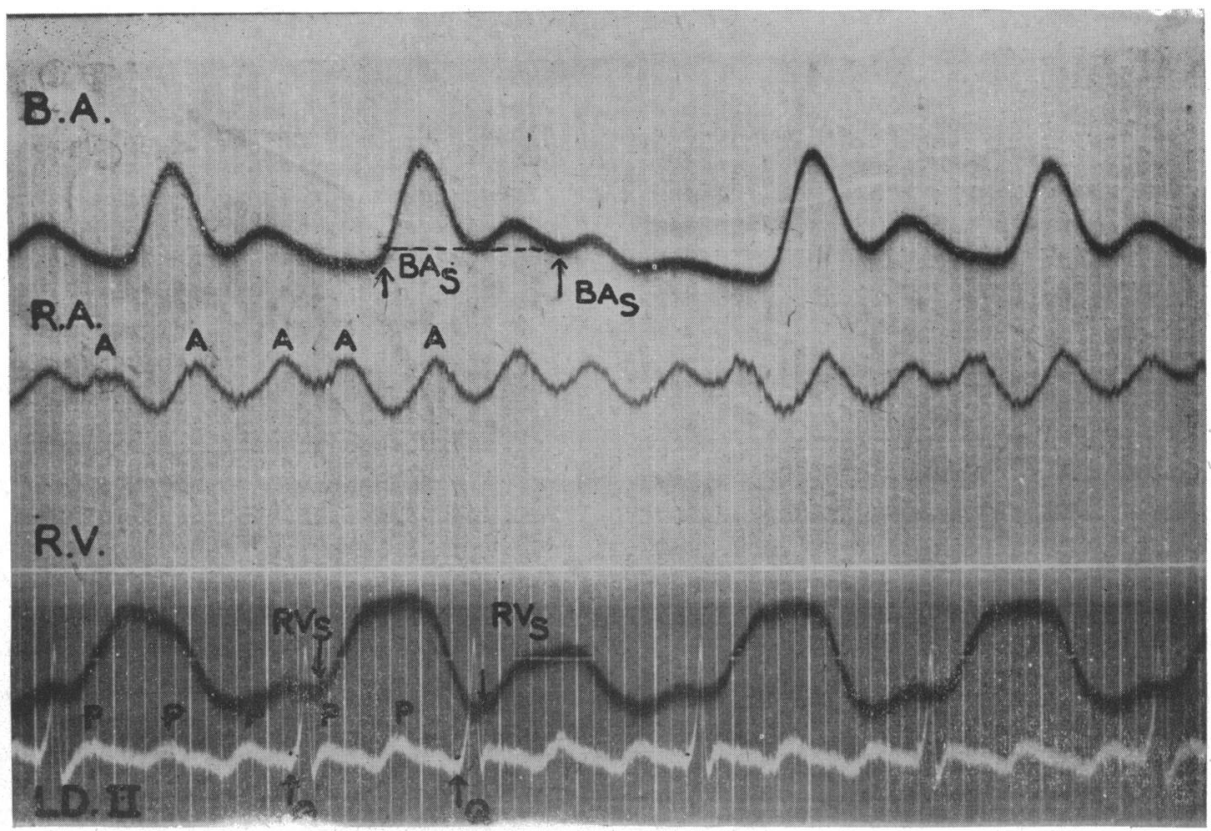

Fig. 14.-Auricular flutter. Record illustrating electrical-mechanical events in a case with 3: 1, 2: 1 A-V response.

From top to bottom, blood pressure tracings in the brachial artery (B.A.), the right atrium (R.A.), the right ventricle (R.V.), and electrocardiogram lead II.

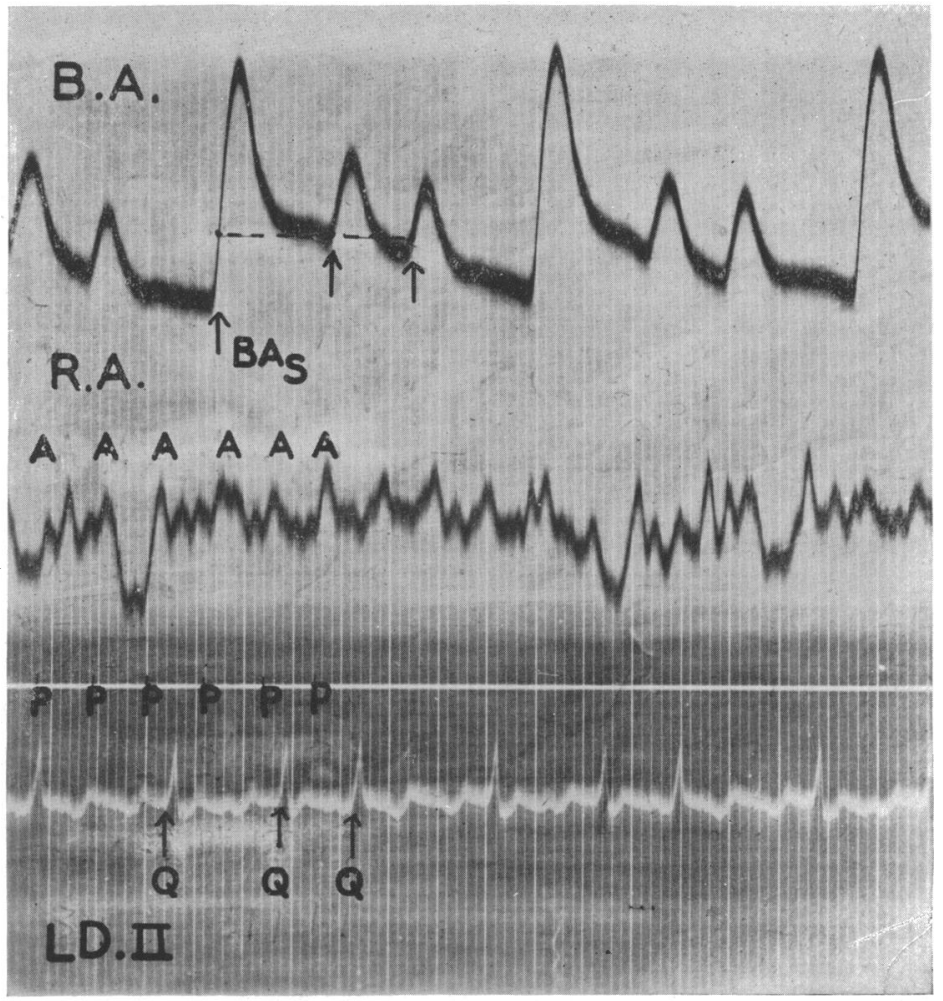

Fig. 15.-Auricular flutter. Record illustrating electrical-mechanical events in a case with $3: 1,2: 1,1: 1 \mathrm{~A}-\mathrm{V}$ ratio.

From top to bottom, blood pressure tracings in the brachial artery (B.A.), the right atrium (R.A.), and electrocardiogram lead II. For discussion see text. 
TABLE VII

Relationship Between Electrical and Mechanical Events in Two Cases of Complete Heart Block

\begin{tabular}{|c|c|c|c|c|c|c|c|}
\hline & & & & & & Case 254 & Case 341 \\
\hline $\begin{array}{l}\text { Auricular rate per minute } \\
\text { Ventricular rate per minute } \\
\text { QRS interval, sec. } \\
\text { P-Ats interval, sec. }\end{array}$ & $\begin{array}{l}. \\
\therefore \\
. \\
. \\
.\end{array}$ & $\begin{array}{l}\because \\
\because \\
\because \\
\because \\
\cdots\end{array}$ & $\begin{array}{l}. \\
\therefore \\
\therefore \\
. \\
.\end{array}$ & $\begin{array}{l}. \\
\cdots \\
\cdots \\
\cdots \\
\cdots\end{array}$ & $\begin{array}{l}. \\
\because \\
\because \\
\cdots \\
\cdots \\
.\end{array}$ & $\begin{array}{l}94 \\
33 \\
0.080 \\
0.090 \\
0.070 \\
0.140\end{array}$ & $\begin{array}{l}86 \\
33 \\
0.090 \\
0.090 \\
0.070 \\
0.150\end{array}$ \\
\hline
\end{tabular}

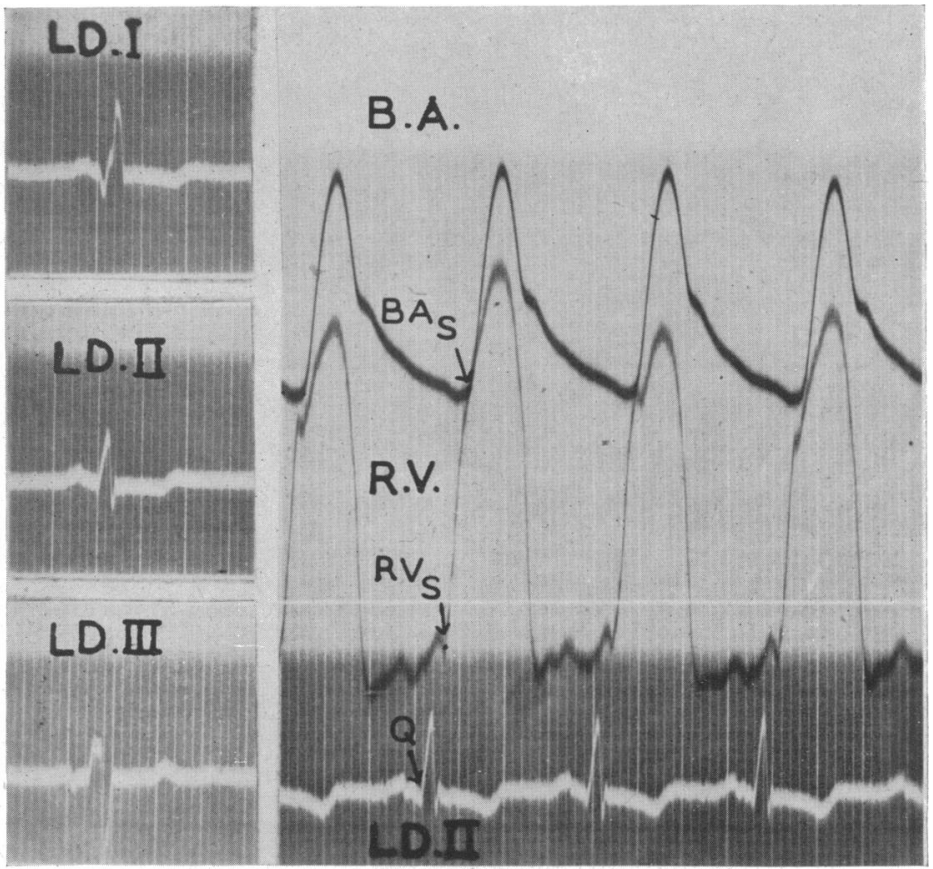

FIG. 16.-Record illustrating electrical-mechanical events in a case with left bundle branch block.

To the left, are the standard leads of the electrocardiogram demonstrating left bundle branch block. Præcordial leads showed delayed peak of $\mathrm{R}$ in V5 and V6. To the right, from top to bottom, are blood pressure tracings in the brachial artery (B.A.), the right ventricle (R.V.), and electrocardiogram lead II. For time intervals see Table VIII, Case 416, and for discussion see text.

Q-BAs times were normal. There was, therefore, no delay and no asynchronism in the pressure buildup of either ventricle. A characteristic tracing of pressure in the right auricle may be seen in Fig. 17. The striking feature was the regular sequence of auricular systoles which occurred at various times in relation to the ventricular cycles. It is seen that the characteristic drop of auricular pressure during ventricular ejection took place at the expected time after the QRS complex. The height of the A wave corresponding to auricular systole was variable, depending on whether or not the ventricle was in systole or diastole, i.e. the tricuspid valve was opened or closed, the largest deflection occurring when the tricuspid valve was closed. (See the first and the last $A$ in lower section of Fig. 17.) In the few instances where a $P$ wave fell approximately $0 \cdot 12$ to $0.20 \mathrm{sec}$. before the QRS complex, the auricular pressure tracing showed the characteristic deflection of an $a$ wave followed by a $c$ wave preceding the descent 


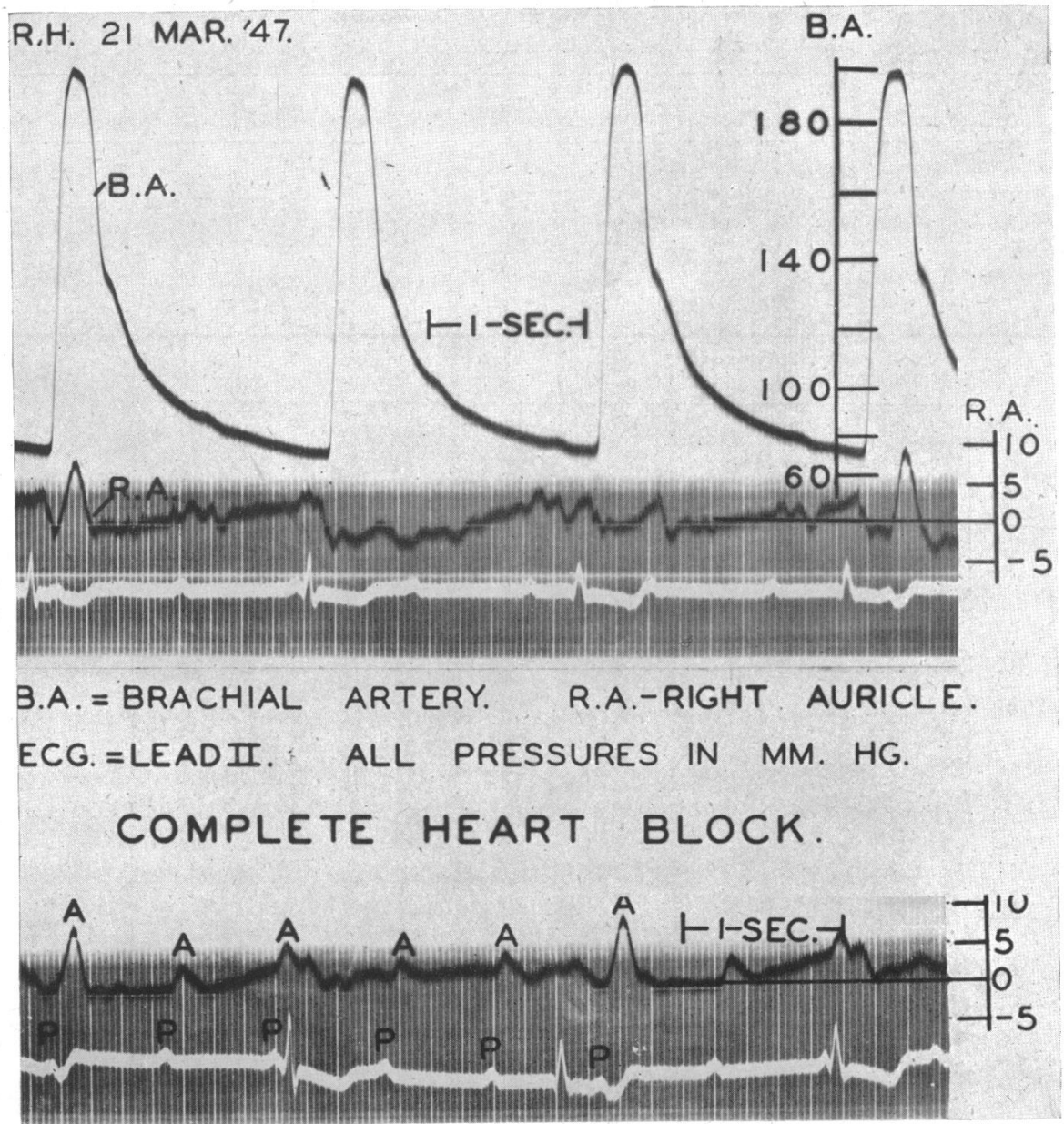

Fig. 17.-Complete heart block. Records illustrating electrical-mechanical events in such a case.

In the upper section from top to bottom, blood pressure tracings in the brachial artery (B.A.), the right atrium (R.A.), and electrocardiogram lead II. In the lower section, blood pressure tracings in the right atrium (R.A.) and electrocardiogram lead II.

of the base. (See the third A from the left in lower section of Fig. 17.)

(b) Incomplete $A-V$ heart block. Incomplete A-V heart block with prolongation of the PR interval was observed in a patient with generalized scleroderma involving the heart and lungs (Fig. 18). The duration of the $\mathbf{P}$ wave was normal and the $\mathbf{P}-\mathbf{R}$ interval was prolonged to $0.25 \mathrm{sec}$. The $\mathrm{P}-\mathrm{AT}_{\mathrm{s}}$ time was lengthened to $0.16 \mathrm{sec}$., whereas the $Q-R V_{s}$ and $\mathrm{Q}-\mathrm{BA}_{s}$ times were normal, $0.08 \mathrm{sec}$. and 0.14 to $0 \cdot 16$ sec. respectively. The lengthening of the $P-A T_{s}$ time suggests that there was abnormality in contraction of the auricle and apparently no difficulty in conduction within the auricular muscle as evidenced by the normal width of the $\mathrm{P}$ wave. In a previous publication, Cournand et al. (1946), the prolonged $\mathrm{Q}-\mathrm{RV}_{\mathrm{s}}$ time reported was incorrect as subsequent examination revealed the portion of the tracing read to be damped.

(c) Bundle branch block. Ventricular asynchronism in the presence of bundle branch block has been demonstrated by several authors, using the peripheral arterial pulse wave or stethogram recorded simultaneously with the electrocardiogram. More complete data pertaining to this type of asynchronism can be added by comparison of the $Q-R$ and

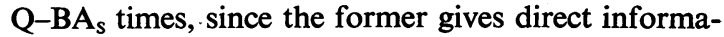
tion concerning contraction of the right ventricle and 


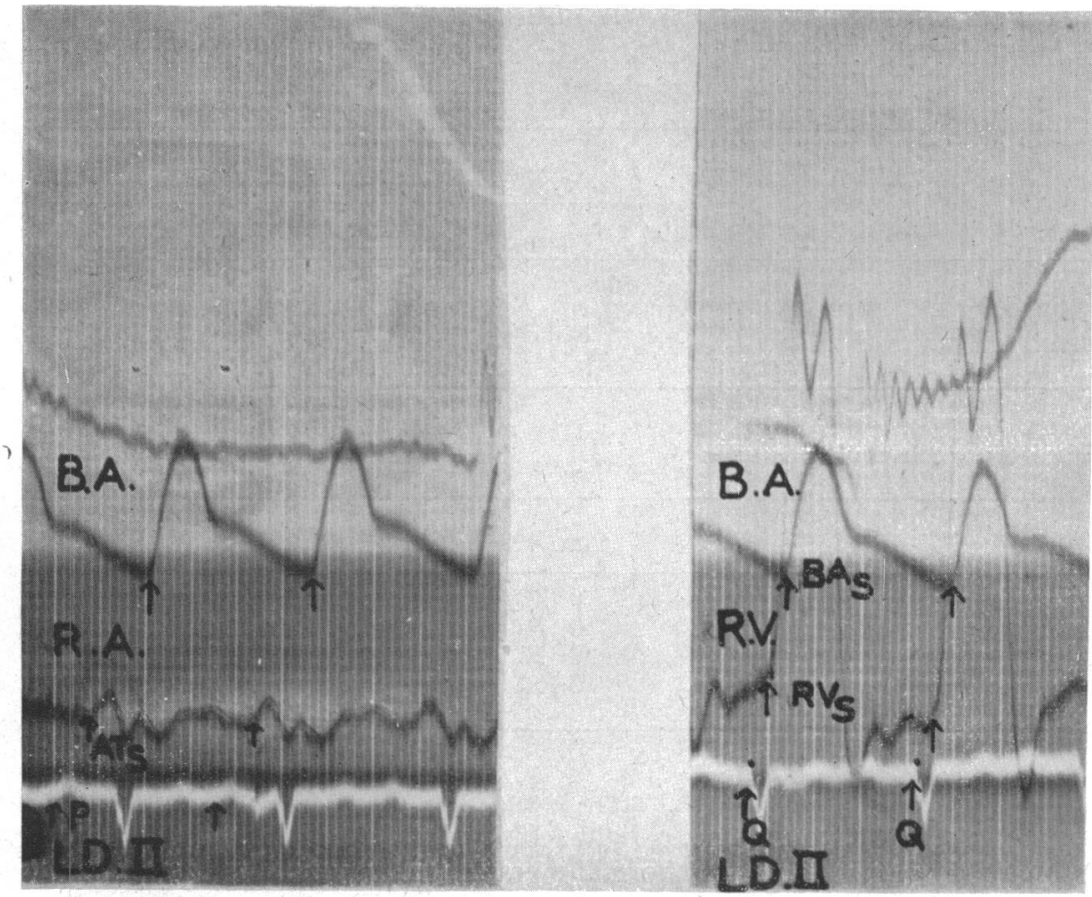

FIG. 18.-Record illustrating electrical-mechanical events in a case with incomplete A-V block (prolonged P-R interval) associated with generalized scleroderma involving the heart and lungs. In the section to the left, from top to bottom, pneumogram, blood pressure tracings from the brachial artery (B.A.), the right atrium (R.A.), and electrocardiogram lead II. In the section to the right, pneumogram, blood pressure tracings from the brachial artery (B.A.), the right ventricle (R.V,), and electrocardiogram lead II. For discussion see text.

the latter indirect information concerning left ventricular contraction.

(i) Left bundle branch block. Three patients with hypertensive and arteriosclerotic heart disease, congestive heart failure, and left bundle branch block were studied and the data is presented in Table VIII and one case (416) is illustrated in Fig. 16. The time intervals in the three cases suggest a normal contraction time of the right ventricle and delayed contraction of the left ventricle, consistent with the ventricular asynchronism expected with left bundle branch block.

(ii) Right bundle branch block. In two cases, right bundle branch block was induced following the oral administration of $0.80 \mathrm{~g}$. of quinidine sulphate. The electrocardiogram and blood pressure tracings, therefore, could be compared before and after the appearance of the bundle branch block. The data may be found in Table IX. In the first case, a 21 year old girl with an interventricular septal defect,

TABLE VIII

Relationship Between Electrical and Mechanical Events in Three Cases of Left Bundle Branch BLOCK

\begin{tabular}{|c|c|c|c|c|c|c|c|}
\hline & & & & & Case $306^{*}$ & Case 261 & Case 416 \\
\hline $\begin{array}{l}\text { QRS interval, sec. } \\
\text { Q-RV } \\
\text { Q-BAs interval, sec. } \\
\text { Q-FA interval, sec. } \\
\text { - FA interval, sec. }\end{array}$ & $\begin{array}{l}\cdots \\
\cdots \\
\cdots\end{array}$ & $\begin{array}{l}\cdots \\
\cdots \\
\cdots \\
\cdots\end{array}$ & $\begin{array}{l}\ddot{*} \\
\cdots \\
\cdots\end{array}$ & $\begin{array}{l}\cdots \\
\cdots \\
\cdots \\
\cdots\end{array}$ & $\begin{array}{c}0.120 \\
0.070 \\
0.200 \dagger \text { and } 0.230 \dagger\end{array}$ & $\begin{array}{l}0 \cdot 160 \\
0.090 \\
0 \cdot 220\end{array}$ & $\begin{array}{l}0 \cdot 120 \\
0.090 \\
0 \cdot 240\end{array}$ \\
\hline
\end{tabular}

* A case with pulsus alternans.

$\dagger$ Time interval variation corresponding to strong and weak beats of pulsus alternans (see text).

C 
TABLE IX

Relationship Between Electrical and Mechanical Events in Right Bundle Branch Block Right Bundle Branch Block induced by Quinidine

\begin{tabular}{|c|c|c|c|c|c|c|}
\hline & & & \multicolumn{2}{|c|}{ Case 333} & \multicolumn{2}{|c|}{ Case 351} \\
\hline & & & Control & R.B.B.Bl. & Control & R.B.B.Bl. \\
\hline $\begin{array}{l}\text { QRS interval, sec. } \\
\text { Q-RV } \\
\text { Q-BA interval, sec. } \\
\text {-BA interval, sec. }\end{array}$ & $\begin{array}{l}\cdots \\
\cdots \\
\cdots\end{array}$ & $\begin{array}{l}\cdots \\
\cdots \\
\cdots\end{array}$ & $\begin{array}{l}0.060 \\
0.070 \\
0 \cdot 170\end{array}$ & $\begin{array}{l}0 \cdot 120 \\
0 \cdot 110 \\
-\end{array}$ & $\begin{array}{l}0 \cdot 105 \\
0.070 \\
0 \cdot 190\end{array}$ & $\begin{array}{l}0 \cdot 120 \\
0 \cdot 110 \\
0 \cdot 190\end{array}$ \\
\hline
\end{tabular}

Right Bundle Branch Block in Cases with Arteriosclerotic Heart Disease and Cor Pulmonale (Case 440) and with 2: 1 $A-V$ Block (Cases 302 and 268)

\begin{tabular}{|c|c|c|c|c|c|c|}
\hline & & & , & Case 440 & Case 302 & Case 268 \\
\hline $\begin{array}{l}\text { QRS interval, sec. } \\
\text { Q-RV interval, sec. } \\
\text { Q-PAs Interval, sec. } \\
\text { Q-BAs interval, sec. }\end{array}$ & $\begin{array}{l}\cdots \\
\cdots \\
\cdots \\
\cdots\end{array}$ & $\begin{array}{l}\cdots \\
\cdots \\
\cdots \\
\cdots\end{array}$ & $\begin{array}{l}\cdots \\
\cdots \\
\cdots\end{array}$ & $\begin{array}{l}0 \cdot 140 \\
0 \cdot 130 \\
0 \cdot 150 \\
0 \cdot 130\end{array}$ & $\begin{array}{l}0 \cdot 160 \\
0 \cdot 120 \\
\overline{0 \cdot 170}\end{array}$ & $\begin{array}{l}0 \cdot 170 \\
0 \cdot 105 \\
\overline{0.240}\end{array}$ \\
\hline
\end{tabular}

the control tracings showed normal electrical complexes and time intervals. After quinidine, a right bundle branch block developed and the normal $\mathrm{Q}-\mathrm{RV}_{\mathrm{s}}$ time of $0.070 \mathrm{sec}$. was prolonged to $0 \cdot 110$ sec. In the second case, a 60 year old man with arteriosclerosis and an old myocardial infarct, the control electrocardiogram showed evidence of myocardial damage and early incomplete bundle branch block, characterized by a QRS of $0 \cdot 105 \mathrm{sec}$. in lead II and a delayed peak of the $R$ wave over the left præcordium. Before administration of quinidine, the Q- $\mathbf{R V}_{\mathbf{s}}$ time was normal but the Q-BA time was slightly prolonged, confirming the electrocardiographic diagnosis of early incomplete left bundle branch block. After quinidine, an $\mathrm{S}$ wave appeared in lead $I$ and the QRS complex increased in that lead to $0.120 \mathrm{sec}$. The $\mathrm{Q}-\mathrm{BA}_{\mathrm{s}}$ time remained unchanged but the Q-RV time increased from $0.070 \mathrm{sec}$. to 0.110 sec. (Fig. 7). In Fig. 19 (Table IX, Case 440) is illustrated an additional case of right bundle branch block observed in a patient with arteriosclerotic heart disease and cor pulmonale, in which a markedly prolonged $\mathrm{Q}-\mathrm{RV}_{\mathrm{S}}$ time is seen.

In summary, intracardiac and intra-arterial blood pressure tracings recorded simultaneously with the electrocardiogram demonstrated clearly the presence of ventricular asynchronism in bundle branch block.

These findings confirm and add to the observations of various authors (Castex et al., 1941; Battro et al., 1936; Katz et al., 1927 and 1935; Kossman et al., 1947; Nichol, 1933; and Wolferth et al., 1935) who have studied mechanical and electrical relationships in bundle branch block. Various types of simultaneous tracings were employed by these authors and include electrocardiograms, peripheral artery blood pressure tracings, and in a few instances stethograms, phlebograms, and apical cardiograms. They found that in left bundle branch block there was a prolongation of the " ejection time" which corresponded to the prolongation of the $\mathrm{Q}-\mathrm{BA}_{\mathrm{s}}$ time found in the present study. In right bundle branch block the "ejestion time" remained essentially normal. Data concerning the events in the right ventricle was obtained by indirect means and is subject to interpretation.

(d) Right bundle branch block with incomplete 2:1 $A-V$ block. In 2 patients a 2: 1 A-V block was associated with right bundle branch block. In addition, one of these patients had short periods of complete heart block. The data in these two cases may be found in Table IX. In the first case the duration of the QRS complex was 0.160 sec., the ventricular complexes were of the aberrant type with downward deflection in lead I and upward deflection in lead III, suggesting that the stimulation arrived first in the left ventricle. The $\mathrm{Q}-\mathrm{RV}_{\mathrm{s}}$ time was significantly prolonged to $0.120 \mathrm{sec}$. while the $\mathrm{Q}-\mathrm{BA}_{s}$ time was normal $(0 \cdot 170 \mathrm{sec}$. $)$.

In the second case (Fig. 20 and 21 and Table IX, Case 268) during the periods of incomplete 2:1 heart block the $\mathrm{P}-\mathrm{R}$ interval was markedly prolonged to $0.310 \mathrm{sec}$. The $\mathrm{Q}-\mathrm{RV}_{\mathrm{s}}$ and $\mathrm{Q}-\mathbf{B A}_{\mathrm{s}}$ times were both lengthened to $0 \cdot 105$ and $0 \cdot 240$ sec., respectively. During the period of complete heart block with an auricular rate of 71 and a ventricular rate of 27 , the ventricular complexes were of the same aberrant configuration and the same duration, again with downward deflection in lead I, upward in lead III. 


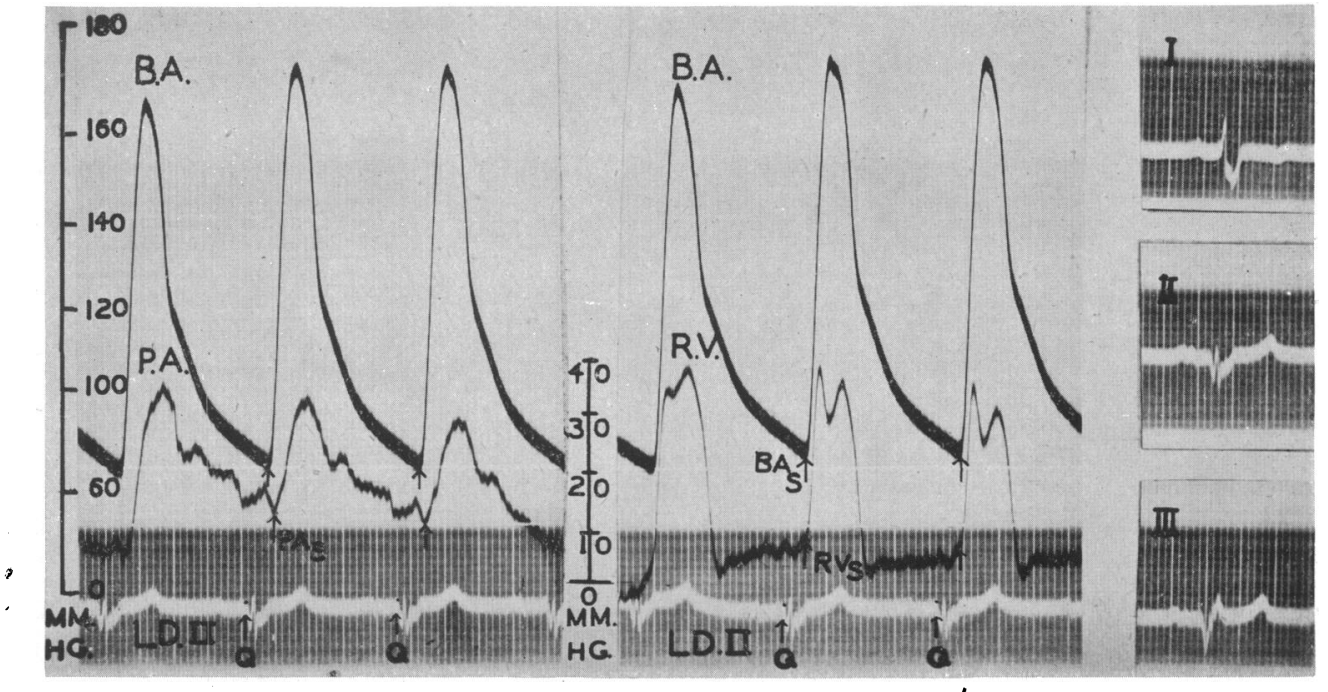

Fig. 19.-Records illustrating electrical-mechanical events in a case with right bundle branch block. To the right, are the standard leads of the electrocardiogram demonstrating right bundle branch block. In the centre, are blood pressure tracings in the brachial artery (B.A.), the right ventricle (R.V.), and electrocardiogram lead II. To the left, are blood pressure tracings in the brachial artery (B.A.), the pulmonary artery (P.A.), and electrocardiogram lead II.

Note, as in Fig. 3, the ascending slopes of the right ventricle and pulmonary artery do not coincide. For figures see Table IX, Case 440. For discussion see text.

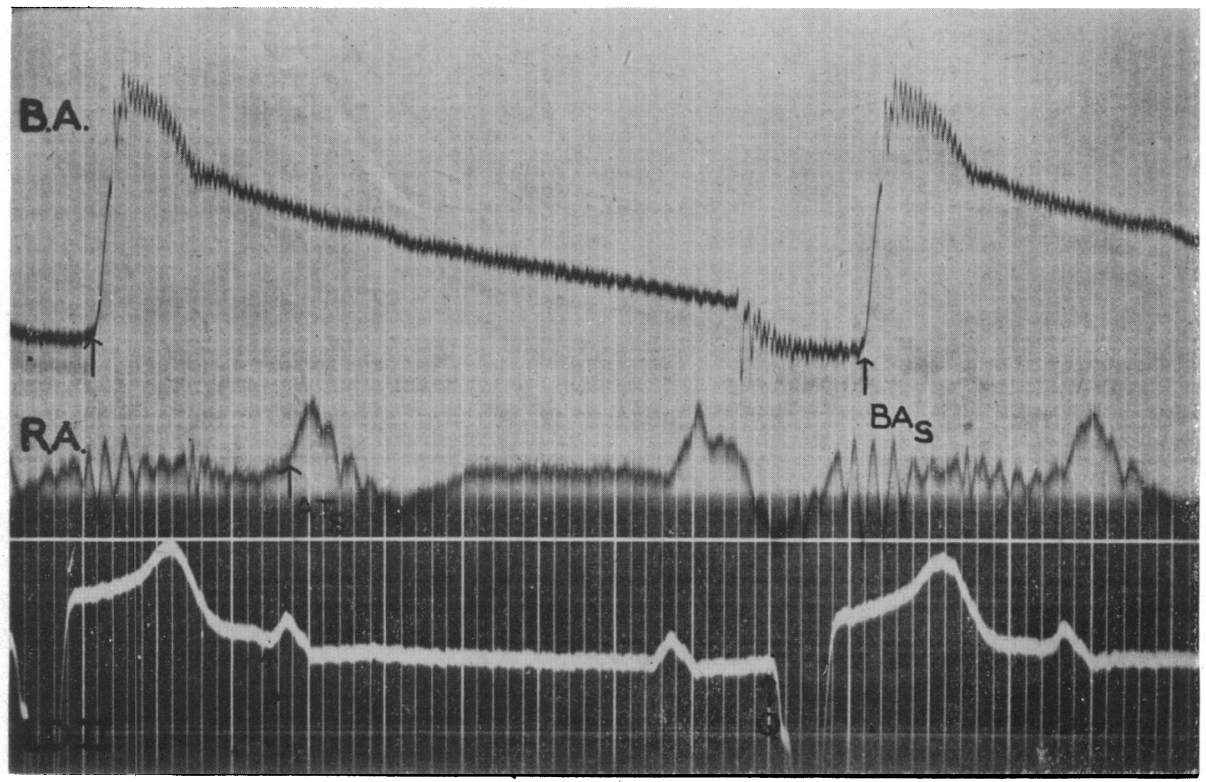

FIG. 20.--Records illustrating electrical-mechanical events in a case with right bundle branch block and 2:1 A-V block.

From top to bottom, blood pressure tracings in the brachial artery (B.A.), the right atrium (R.A.), and electrocardiogram lead II.

For data see Table IX, Case 268, and for discussion see text. 


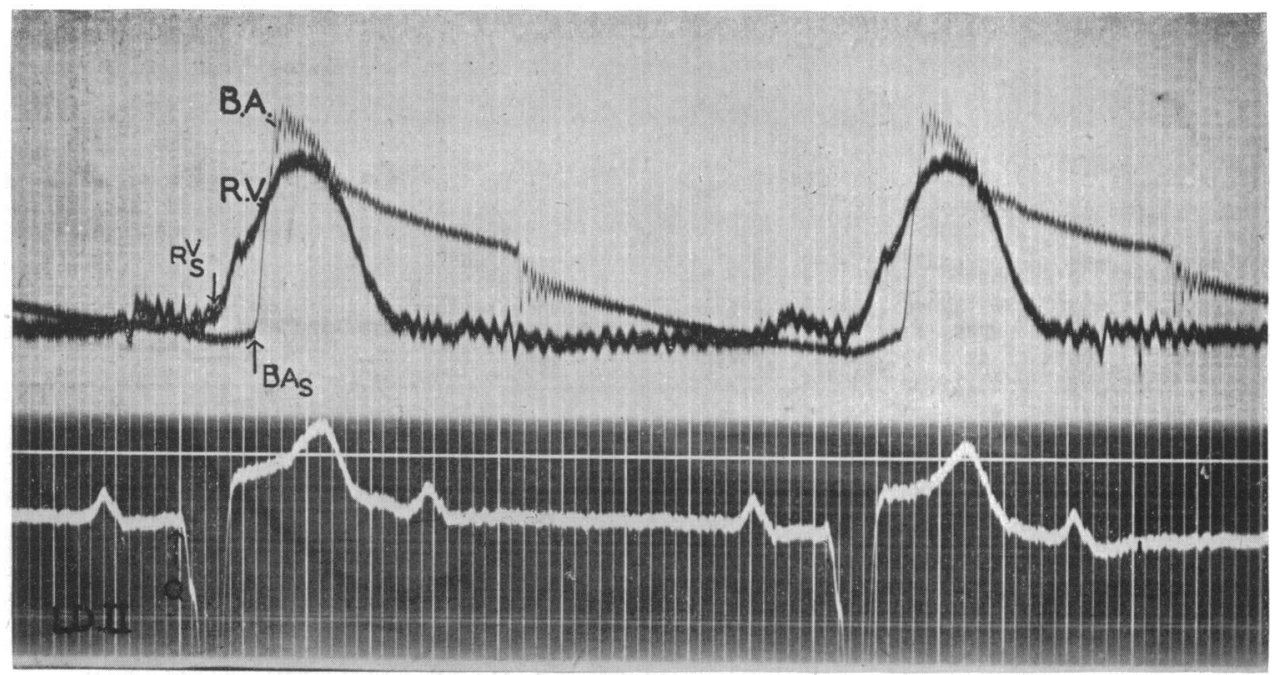

FIG. 21.-Records illustrating electrical-mechanical events in a case with right bundle branch block and 2: $1 \mathrm{~A}-\mathrm{V}$ block.

From top to bottom, blood pressure tracings in the brachial artery (B.A.), the right ventricle (R.V.), and electrocardiogram lead II.

For data see Table IX, Case 268, and for discussion see text.

This suggests that ventricular depolarization was the same as during incomplete A-V block, and that the idioventricular focus was probably in the His bundle. The $\mathbf{Q}-\mathbf{R V}_{\mathbf{s}}$ and $\mathbf{Q}-\mathrm{BA}_{\mathbf{s}}$ time intervals were unchanged. During both complete and incomplete $\mathrm{A}-\mathrm{V}$ block the duration of $\mathrm{P}-\mathrm{AT}_{\mathrm{s}}$ time was short $(0.050 \mathrm{sec})$, see Fig. 20, indicating no abnormality of auricular contraction, in contrast to the findings in the case with incomplete $\mathrm{A}-\mathrm{V}$ block previously described.

These two patients are of particular interest because during a period of 2:1 block with right bundle branch block the electrocardiographic patterns were identical. In the first case there was a delay in right ventricular contraction, whereas in the second case slow spread of stimulation or delay in contraction existed in both ventricles.

\section{(6) Pulsus Alternans}

One case of hypertensive and arteriosclerotic heart disease with left bundle branch block showed evidence of pulsus alternans of the mechanical type. The findings in this case (306) are illustrated in Fig. 22 and the data listed in Tables VIII and X. In the femoral artery tracings there was a variation in the systolic peak which occurred in a regular manner and may be interpreted as a succession of strong and weak beats. In contrast there was a steady level of the systolic peaks in the right ventricle. There was no evidence in the electrocardiogram of electrical alternation. The duration of the QRS complex in alternate beats remained the same and the $\mathrm{Q}-\mathrm{RV}_{\mathrm{s}}$ time also did not vary. The striking abnormality was the rhythmic variation of the $Q-B_{s}$ time. This interval was shorter for the beat corresponding to the high systolic peak and longer for the beat corresponding to the lower systolic peak. These variations in pressure as well as the variations in the Q-BA time, occurring rhythmically without any variation in the duration of the QRS complex, suggest a less efficient ventricular contraction every other beat. However, it is not possible to eliminate

TABLE $X$

Relationship Between Electrical and Mechanical Events in Patient with Pulsus Alternans (CASE 306)

\begin{tabular}{llllll|l|c|c}
\hline & & & & & & & Strong beat & Weak beat \\
\hline QRS interval, sec. & $\ldots$ & $\ldots$ & $\ldots$ & $\ldots$ & $\ldots$ & $\ldots$ & 0.120 & 0.120 \\
Q-RV interval, sec. & $\ldots$ & $\ldots$ & $\ldots$ & $\ldots$ & $\ldots$ & $\ldots$ & 0.070 & 0.070 \\
Q-FAs interval, sec. &. & $\ldots$ & $\ldots$ & $\ldots$ & $\ldots$ & $\ldots$ & 0.200 & $\mathbf{0 . 2 3 0}$ \\
\hline
\end{tabular}




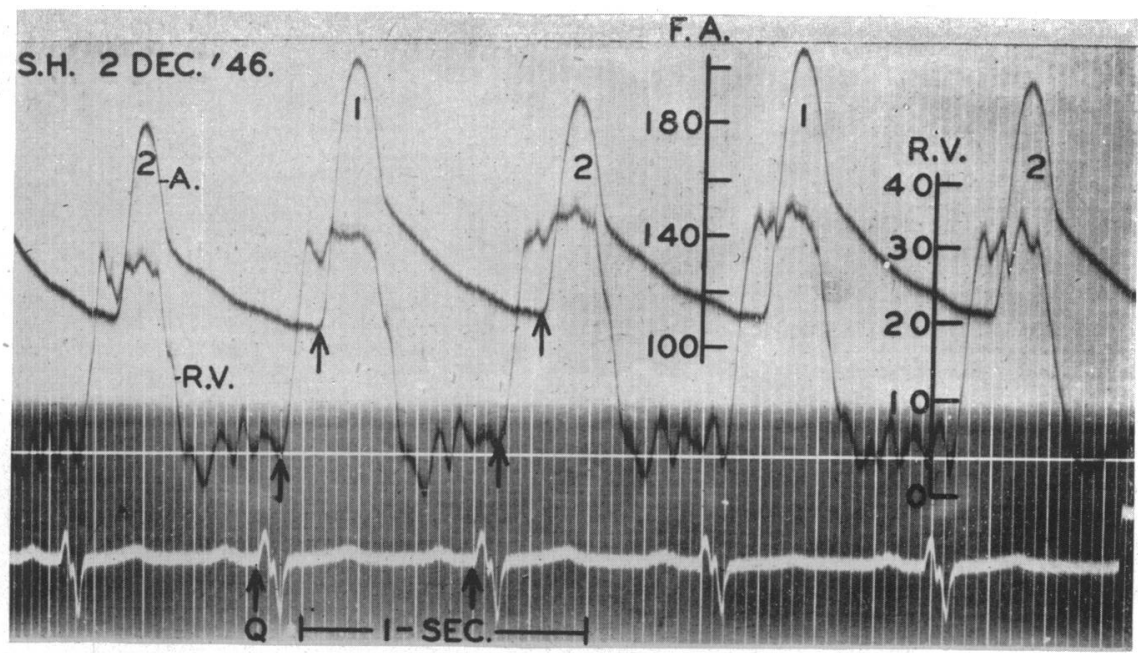

FIG. 22.-Pulsus alternans. Records illustrating electrical-mechanical events in such a case. From top to bottom, blood pressure tracings in the femoral artery, the right ventricle, and electrocardiogram lead II. No. 1 corresponds to the strong beat and No. 2 to the weak beat.

Note absence of alternation of pressure in right ventricle. For data see Tables VIII and X, Case 306, and for discussion see text.

F.A. = Femoral artery. $\quad$ R.V. = Right ventricle. $\quad$ All pressures in $\mathrm{mm} . \mathbf{H g}$.

Electrocardiogram, lead II.

as a factor rhythmic variation of peripheral vascular tone of reflex origin, which would ultimately influence the curve of blood ejection from the left ventricle into the aorta and the pulse wave velocity.

\section{Summary AND CONClusions}

The relationship between electrical and mechanical events in the cardiac cycle was studied in normal subjects, in children with congenital heart disease, and in adults with cardiovascular disease.

In children the intervals were shorter than those of normal adults. The prolongation of the isometric contraction of the right ventricle in children with congenital heart disease seemed to be dependent upon hypertension of the lesser circulation.

In adults with heart disease who had normal sinus rhythm and no conduction abnormalities, the time intervals were identical with those found in normal adults unless they were in congestive failure with hypertension of the lesser circulation. In this event the Q-PA time interval was slightly prolonged and the duration of isometric contraction of the right ventricle was also longer than normal.

Abnormalities of rhythm, conduction, and contraction encountered in patients with cardiovascular disease were also analysed and the following points deserve emphasis.

(a) Ventricular premature contractions apparently produce two types of asynchronism with a lag in one or the other ventricle. It is difficult to interpret the relationship between electrical configuration of the premature contractions and the mechanical events, since premature beats with electrocardiographic patterns identifying them as arising from opposite ventricles produced the same type of ventricular asynchronism.

(b) In chronic auricular fibrillation, in addition to the complete arrhythmia, disturbances of the contraction mechanism of both ventricles were present.

(c) In auricular flutter the time intervals remained constant and normal during pure flutter with a constant $\mathrm{A}-\mathrm{V}$ ratio. Minor variations in the $\mathrm{Q}-\mathrm{RV}_{\mathrm{s}}$ and $\mathbf{Q}-\mathbf{B A}_{\mathbf{s}}$ intervals as well as variations in right ventricular and brachial artery systolic pressures were found when the degree of block varied.

(d) In cases of complete heart block with bundle of His ventricular rhythm the auricular and ventricular electrical-mechanical intervals remained normal even though the conduction defect consisted of complete $\mathrm{A}-\mathrm{V}$ dissociation. In uncomplicated bundle branch block ventricular asynchronism of the expected type was found. However, in one patient with both incomplete 2:1 A-V block and right bundle branch block there was a delay in onset of the mechanical systole in both ventricles.

Acknowledgment is made of the assistance of $H$. $L$. Motley, D. T. Dresdale, H. M. Weiner, and A. Himmelstein, in the recording of blood pressure tracings. 


\section{REFERENCES}

Battro, A., Braun-Menendez, E., and Orias, O. (1936). Rev. Argent. Cardiol., 3, 325.

Bloomfield, R. A., Lawson, H. D., Cournand, A., Breed E. S., and Richards, D. W., Jr. (1946). J. Clin. Invest., 25, 639.

Castex, M. R., Battro, A., and Gonzales, R. (1941). Arch. intern. Med., 67, 76.

Cournand, A., and Ranges, H. (1941). Proc. Soc. exp. Biol. N.Y., 46, 462.

Lawson, H. D., Bloomfield, R. A., Breed, E. S. and Baldwin, E. de F. (1944). Ibid., 55, 34.

- Bloomfield, R. A., and Lawson, H. D. (1945). Ibid., 60, 73.

_-, Motley, H. L., Himmelstein, A., Dresdale, D., and Richards, D. W., Jr. (1946). Ibid., 63, 148.

Katz, L. N., and Feil, H. S. (1923). Arch. intern. Med., $32,672$.

-, and Weinman, S. F. (1927). Amer. Heart J., 81, 360.
Katz, L. N., Landt, H., and Bohning, A. (1935). Amer. Heart J., 10, 681 .

Kossman, C. E., and Goldberg, H. H. (1947). Ibid., 33, 308.

Lewis, T. (1925). The Mechanism and Graphic Registration of the Heart Beat. London, Shaw \& Sons, Ltd.

Miller, A., and White, P. D. (1941). Amer. Heart J., 21, 504.

Nichol, A. D. (1933). Ibid., 9, 72.

Wiggers, C. J. (1923). Circulation in Health and Disease, 2nd edit. Philadelphia, Pa., Lea \& Febiger.

- (1928). Pressure Pulses in the Cardiovascular System. London and New York, Longmans, Green and Co.

(1944). Physiology in Health and Disease, 4th edit. Philadelphia, Pa., Lea \& Febiger.

Wolferth, C. C., and Margolies, A. (1935). Amer. Heart $J ., 10,425$. 